OPEN ACCESS

Edited by:

Cecil Czerkinsky,

University of Nice - Sophia

Antipolis, France

Reviewed by:

Vincenzo Cerundolo,

University of Oxford, UK

Marielle C. Gold,

Oregon Health \& Science University,

USA

*Correspondence:

Marcelo B. Sztein,

Center for Vaccine Development,

University of Maryland School of

Medicine, 685 West Baltimore Street,

HSF-1 Room 480, Baltimore,

MD 21201, USA

msztein@medicine.umaryland.edu

Specialty section:

This article was submitted to Mucosal Immunity, a section of the journal

Frontiers in Immunology

Received: 03 June 2015

Accepted: 26 August 2015

Published: 17 September 2015

Citation:

Booth JS, Salerno-Goncalves $R$, Blanchard TG, Patil SA, Kader HA, Safta AM, Morningstar LM, Czinn SJ, Greenwald BD and Sztein MB (2015) Mucosal-associated invariant T cells

in the human gastric mucosa and blood: Role in Helicobacter pylori infection.

Front. Immunol. 6:466. doi: 10.3389/fimmu.2015.00466

\section{Mucosal-associated invariant $T$ cells in the human gastric mucosa and blood: Role in Helicobacter pylori infection}

\author{
Jayaum S. Booth ${ }^{1,2}$, Rosangela Salerno-Goncalves ${ }^{1,2}$, Thomas G. Blanchard ${ }^{2}$, \\ Seema A. Patil ${ }^{3,4}$, Howard A. Kader ${ }^{2}$, Anca M. Safta ${ }^{2}$, Lindsay M. Morningstar', \\ Steven J. Czinn ${ }^{2}$, Bruce D. Greenwald ${ }^{3,4}$ and Marcelo B. Sztein ${ }^{1,2,3 *}$
}

${ }^{1}$ Center for Vaccine Development, University of Maryland School of Medicine, Baltimore, MD, USA, ${ }^{2}$ Department of Pediatrics, University of Maryland School of Medicine, Baltimore, MD, USA, ${ }^{3}$ Department of Medicine, University of Maryland School of Medicine, Baltimore, MD, USA, ${ }^{4}$ Division of Gastroenterology and Hepatology, University of Maryland School of Medicine, Baltimore, MD, USA

Mucosal-associated invariant T (MAIT) cells represent a class of antimicrobial innate-like $\mathrm{T}$ cells that have been characterized in human blood, liver, lungs, and intestine. Here, we investigated, for the first time, the presence of MAIT cells in the stomach of children, adults, and the elderly undergoing routine endoscopy and assessed their reactivity to Helicobacter pylori (H. pylori - Hp), a major gastric pathogen. We observed that MAIT cells are present in the lamina propria compartment of the stomach and display a similar memory phenotype to blood MAIT cells. We then demonstrated that gastric and blood MAIT cells are able to recognize H. pylori. We found that $\mathrm{CD}^{+}$and $\mathrm{CD} 4^{-} \mathrm{CD} 8^{-}$(double negative) MAIT cell subsets respond to $H$. pylori-infected macrophages stimulation in a MR-1 restrictive manner by producing cytokines (IFN- $\gamma$, TNF- $\alpha$, IL-17A) and exhibiting cytotoxic activity. Interestingly, we observed that blood MAIT cell frequency in $\mathrm{Hp}^{+v e}$ individuals was significantly lower than in $\mathrm{Hp}^{-v e}$ individuals. However, gastric MAIT cell frequency was not significantly different between $\mathrm{Hp}^{+v e}$ and $\mathrm{Hp}^{-v e}$ individuals, demonstrating a dichotomy between blood and gastric tissues. Further, we observed that the majority of gastric MAIT cells (>80\%) expressed tissue-resident markers (CD69+ CD103+), which were only marginally present on PBMC MAIT cells $(<3 \%)$, suggesting that gastric MAIT cells are readily available to respond quickly to pathogens. These results contribute important new information to the understanding of MAIT cells function on peripheral and mucosal tissues and its possible implications in the host response to $\mathrm{H}$. pylori.

Keywords: gastric MAIT, stomach, cytotoxic, H. pylori, age-related

\section{Introduction}

Innate $\mathrm{T}$ cells are distinct from conventional $\mathrm{T}$ cells in that they have a limited repertoire diversity and that their responses display innate-like properties (1). Three subsets of innate $\mathrm{T}$ cells have been implicated in detection and response to pathogens, i.e., natural killer T cells (NKT), gamma-delta $(\gamma \delta) \mathrm{T}$ cells, and mucosal-associated invariant T (MAIT) cells (2-4). These cell subsets are phylogenetically 
conserved, express defined chemokine receptors, and are localized in peripheral tissues, particularly in mucosal tissues $(5,6)$. While NKT and $\gamma \delta$ T cells have been studied extensively, much less information is available regarding MAIT cells characterization and function. In humans, intestinal innate $\mathrm{T}$ cells have been described in two distinct compartments: the lamina propria (LP) and the epithelial layer $(5,7)$. Although NKT and $\gamma \delta$ T cells have been characterized in the gastric mucosa $(8,9)$, the presence of MAIT cells has not been reported. We have previously shown that gastric LP mononuclear cells (LPMCs) obtained from healthy volunteers contained more $\mathrm{CD} 8^{+} \mathrm{T}$ cells than $\mathrm{CD}^{+} \mathrm{T}$ cells, making the presence of $\mathrm{CD}^{+}$MAIT cells in the gastric milieu a distinct possibility (10).

Mucosal-associated invariant $\mathrm{T}$ cells are unique MHC-Ibrestricted $\mathrm{T}$ lymphocytes that express a semi-invariant $\mathrm{T}$-cell receptor (V $\alpha 7.2$ in humans) together with high levels of the NK receptor CD161. While the majority of MAIT cells display a CD8 ${ }^{+}$ ( $\alpha \alpha$ or $\alpha \beta$ ) phenotype, double-negative (DN; $\mathrm{CD}^{-} \mathrm{CD} 8^{-}$) and $\mathrm{CD} 4^{+}$MAIT cells have also been reported (11). MAIT cells have been described as effector memory cells $(5,12)$. Recent studies have shown that human MAIT cells have the capacity to react rapidly to pathogens by producing IFN- $\gamma$ and TNF- $\alpha$ in response to antigen-presenting cells (APCs) infected with several organisms, including Mycobacterium tuberculosis, Salmonella enterica serovar Typhimurium, and Salmonella typhi $(4,13,14)$. MAIT cells do not, however, react to all pathogens (4). For example, MAIT cells were unable to respond to either Listeria monocytogenes or Streptococcus (4).

Helicobacter pylori (H. pylori) is a Gram-negative, microaerophilic bacterium that colonizes the human stomach, establishing a chronic infection in about two-thirds of the World population (15). H. pylori infection increases the risk for several clinical disorders such as gastritis, peptic ulcer, and gastric adenocarcinoma (15). The present investigations were undertaken to determine whether MAIT cells, if present in the gastric mucosa, might play a role in $H$. pylori infection. The presence of the riboflavin synthesis pathway in $H$. pylori supports the notion that these bacteria could produce the ligands required for stimulation of MAIT cells.

In this study, we showed for the first time that MAIT cells are present in the human gastric mucosa and display a memory phenotype similar to that observed in blood. Furthermore, we demonstrated that $\mathrm{CD}^{+}$and DN MAIT subsets are activated, in an MR-1-restricted manner, by $H$. pylori-infected macrophages $(\mathrm{M} \phi)$ as evidenced by a robust production of cytokines and cytotoxic ability to lyse $H$. pylori-infected macrophages. We also observed significantly lower frequencies of $\mathrm{CD} 8^{+}$MAIT cells in blood, but not in the gastric mucosa, of $\mathrm{Hp}^{\text {+ve }}$ volunteers when compared with $\mathrm{Hp}^{-v e}$ volunteers. This is the first demonstration of MAIT cell subsets in the human stomach and their response to $H$. pylori infection, significantly extending our understanding of the role of MAIT cells in peripheral and mucosal tissues.

\section{Materials and Methods}

\section{Volunteers}

Volunteers were recruited from the Baltimore-Washington metropolitan area and University of Maryland, Baltimore, campus.
Written informed consent was obtained from volunteers, and all procedures were approved by the University of Maryland, Baltimore Institutional Review Board. Blood and gastric biopsies were collected from 46 clinically indicated esophagogastroduodenoscopy (EGD) volunteers [children: 7-17 years $(n=12)$; adult: $18-64$ years $(n=24)$; elderly: $65-85$ years $(n=10)]$. The indications for EGD included abdominal pain, heartburn, GERD, dysphagia, and acute gastritis. Diagnostic pathology reports showed that the stomach's antral mucosa for the volunteers was either normal or exhibited mild inflammation. No concurrent GI diseases/disorders or other illnesses that may affect the GI tract were present. The presence of $H$. pylori infection was evaluated by culture and rapid urease test (CLO test) (16). All volunteers were $H$. pylori negative except where indicated in the narrative. In addition, PBMC collected from 11 healthy adult volunteers were also used in this study. PBMCs were isolated immediately after blood draws by density gradient centrifugation and cryopreserved in liquid nitrogen following standard techniques (17).

\section{Isolation of LPMCs from Gastric Biopsies}

Gastric LPMCs were isolated as described previously (10). Briefly, after collection of biopsies from clinically indicated EGD volunteers, tissues were treated with $\mathrm{HBSS}$ (without $\mathrm{CaCl}_{2}$, $\mathrm{MgCl}_{2}, \mathrm{MgSO}_{4}$ ) (Gibco, Carlsbad, CA, USA) and EDTA (1 mM; Ambion, Grand Island, NY, USA) to remove intraepithelial cells. LPMCs were then isolated following enzymatic digestion of the biopsies with collagenase D $(100 \mu \mathrm{g} / \mathrm{ml}$; Roche, Indianapolis, IN, USA) and DNase I (10 $\mu \mathrm{g} / \mathrm{ml}$; Affymetrix, Cleveland, $\mathrm{OH}$, USA) and homogenization using the Bullet Blender homogenizer (Next Advance Inc., Averill, NY, USA). Cells were then washed and resuspended in complete medium [RPMI 1640 (Gibco Invitrogen, Carlsbad, CA, USA) supplemented with $10 \%$ heatinactivated fetal bovine serum (BioWhittaker, Walkersville, MD, USA), 2 mM l-glutamine (HyClone, Logan, UT, USA), $2.5 \mathrm{mM}$ sodium pyruvate (Gibco), and $10 \mathrm{mM}$ HEPES (Gibco), $100 \mathrm{U} / \mathrm{ml}$ penicillin (Sigma-Aldrich, St. Louis, MO, USA), $100 \mu \mathrm{g} / \mathrm{ml}$ streptomycin (Sigma-Aldrich), and $50 \mu \mathrm{g} / \mathrm{ml}$ gentamicin (Gibco)] and counted using Kova Glastic Slides (Hycor Biomedical, CA, USA). Cells were either stained immediately for immunophenotyping by flow cytometry or overnight stimulated with mitogens before staining (see below).

\section{H. pylori Growth Conditions}

H. pylori strain 26695 (ATCC, Manassas, VA, USA) was grown on Columbia blood agar (Difco) containing 7\% defibrinated horse blood (Hemostat Laboratories, Dixon, CA, USA), amphotericin $B(2.5 \mu \mathrm{g} / \mathrm{ml})$, and the selective antibiotics trimethoprim $(20 \mu \mathrm{g} / \mathrm{ml})$, vancomycin $(6 \mu \mathrm{g} / \mathrm{ml})$, and cefsulodin $(16 \mu \mathrm{g} / \mathrm{ml})$ (Sigma-Aldrich). Cultures were grown in a designated $\mathrm{CO}_{2}$ incubator with a humidity tray at $37^{\circ} \mathrm{C}$ and $10 \% \mathrm{CO}_{2}$ for 72-96 h. In preparation for coculture assays with THP-1 macrophages, bacteria were transferred to $10 \mathrm{ml}$ Brucella broth (Difco) containing $10 \%$ FBS plus antibiotics in $25-\mathrm{cm}^{2}$ tissue culture flasks overnight. Bacterial density was determined by obtaining readings at an optical density of $450 \mathrm{~nm}(\mathrm{OD}, 450)$ and comparing them to a standardized growth curve, a value of 0.071 corresponding to $1 \times 10^{7}$ bacteria $/ \mathrm{ml}$. 


\section{Preparation of $\boldsymbol{H}$. pylori Lysate Antigen}

$H$. pylori strain 26695 was grown on Columbia agar (Difco) supplemented with $7 \%$ horse blood under microaerobic conditions $\left(5 \% \mathrm{O}_{2}, 10 \% \mathrm{CO}_{2}\right)$ at $37^{\circ} \mathrm{C}$. After $96 \mathrm{~h}$, bacteria were harvested and cultured in tissue culture flasks containing Brucella broth (Difco) supplemented with $10 \%$ fetal bovine serum. Cultures were grown at $37^{\circ} \mathrm{C}$ with $5 \% \mathrm{CO}_{2}$. Bacterial cultures were recovered by centrifugation at $4,000 \times g$ for $20 \mathrm{~min}$ and then suspended in $2 \mathrm{ml}$ phosphate-buffered saline (PBS). Bacteria were lysed by $4 \times 60 \mathrm{~s}$ bursts of power using a probe sonicator (Sonics and Materials Inc., Danbury, CT, USA). Whole bacteria were removed by centrifugation at $5,000 \times g$ for $20 \mathrm{~min}$ and passing the supernatant through a $0.22-\mu \mathrm{m}$ pore filter (18).

\section{Culture, Differentiation, and Infection of THP-1}

The human monocyte cell line THP-1 (ATCC catalog \# TIB-202) was cultured and differentiated as described previously (19). Briefly, THP-1 cells were cultured in complete RPMI described above at $5 \% \mathrm{CO}_{2}$ at $37^{\circ} \mathrm{C}$. THP-1 cells were then differentiated into macrophages $(\mathrm{M} \phi)$ by incubating with phorbol 12-myristate 13-acetate (PMA) (50 ng/ml; Sigma-Aldrich) for $48 \mathrm{~h}$ at $37^{\circ} \mathrm{C}$ in $5 \% \mathrm{CO}_{2}$. The level of cell differentiation was evaluated by surface staining of the cells with antibodies against the classical macrophage marker CD68 (Y1/82A, Biolegend, San Diego, CA, USA). Cells were then washed and incubated overnight in complete RPMI before infection with $H$. pylori. THP-1-differentiated $\mathrm{M} \phi$ were washed in antibiotics-free medium and counted using the viability dye Trypan blue to determine the number of viable THP-1 macrophages. A total of $1 \times 10^{6}$ THP- 1 were incubated in complete RPMI without antibiotics for $4 \mathrm{~h}$ at $37^{\circ} \mathrm{C}$ in $5 \% \mathrm{CO}_{2}$ in the absence or presence of $H$. pylori at 5, 10, 20, 50, and 100 multiplicity of infection (MOI). The infection was stopped by the addition of fresh complete RPMI 1640 medium containing gentamicin $(100 \mu \mathrm{g} / \mathrm{ml}$; Sigma-Aldrich). Cells were then labeled with CD45, a marker present in all hematopoietic cells, to exclude infected $\mathrm{M} \phi$ from flow cytometry analysis. To allow the cells to recover from the infection, infected $\mathrm{M} \phi$ were rested for overnight at $37^{\circ} \mathrm{C}$ before coculturing with PBMC. Negative controls (i.e., non-infected $\mathrm{M} \phi)$ were treated identically except that they were not infected with $H$. pylori. The levels of infection were determined both by flow cytometry using a goat-anti-Helicobacter pylori antiserum (02-03-94, KPL, Gaithersburg, MD, USA) and by bacteria entry assays as described below.

\section{Bacteria Entry Assay}

Bacteria entry experiments were performed as previously described (20). Briefly, after gentamicin treatment, $2 \times 10^{5} \mathrm{M \phi}$ were lysed using $0.1 \%$ saponin in PBS. Lysates were plated in serial dilution on solid GC agar plates supplemented with $10 \%$ horse serum and vancomycin for $48 \mathrm{~h}$ under microaerobic conditions, $10 \% \mathrm{CO}_{2}$ at $37^{\circ} \mathrm{C}$ to detect intracellular bacteria.

\section{Isolation and Culture of Primary Macrophages}

Primary macrophages cells were isolated from PBMC by adhesion to tissue culture plastic plates as described previously (21). Macrophages were $>90 \%$ pure as determined by staining with
CD14 and CD68. Isolated primary macrophages were harvested using a rubber policeman and were then infected with $H$. pylori at MOI of 20. For blocking experiments, $H$. pylori-infected macrophages were pre-treated with anti-MR-1 mAb $(10 \mu \mathrm{g} / \mathrm{ml}$, clone 26.5, Biolegend) or their matched isotype control mouse IgG2a $(10 \mu \mathrm{g} / \mathrm{ml}$, MOPC-173, Biolegend) before coculture with autologous effector cells.

\section{Stimulation of PBMC and Gastric LPMC for Flow Cytometry Analyses}

Ex vivo PBMCs were used as effector cells. Briefly, PBMCs were cocultured with live $H$. pylori (MOI of 50), $H$. pylori lysate (homogenate; $5 \mu \mathrm{g} / \mathrm{ml}$ ), non-infected $\mathrm{M} \phi$, or $H$. pylori-infected M $\phi$ (MOI of 20). The effector:H. pylori-infected M $\phi$ ratios were 50:1, 20:1, 10:1, and 5:1. PBMCs cultured with media only or in the presence of staphylococcal enterotoxin B (SEB) $(10 \mu \mathrm{g} / \mathrm{ml}$ Sigma) were used as negative and positive controls, respectively. Freshly isolated gastric LPMCs were cocultured with media alone, non-infected M $\phi, H$. pylori-infected M $\phi$ (MOI of 20) (Effector: $H$. pylori infected-M $\phi$ ratio was 50:1), or anti-CD3/CD28 beads (positive control; Life technologies, Grand Island, NY, USA). In some experiments (see Results), at the time of stimulation, anti-human CD107a-FITC ( $5 \mu \mathrm{l}$; H4A3, BD, San Jose, CA, USA) was added. After $4 \mathrm{~h}, 0.5 \mu \mathrm{l}$ of Golgi Stop (Monensin, BD, USA) and Golgi Plug (Brefeldin A, BD, USA) were added and cultures continued overnight at $37^{\circ} \mathrm{C}$ in $5 \% \mathrm{CO}_{2}$.

\section{Surface and Intracellular Staining}

Following stimulation, PBMCs and LPMCs were stained for flow cytometry analysis as previously described (10). Following stimulation in the presence of CD107a [LAMP-1, a molecule expressed on the cell membrane which is widely accepted to be associated with cytotoxic T-cell activity (22)), PBMCs and LPMCs were stained for live/dead discrimination (YEVID) (Invitrogen, Carlsbad, CA, USA). Blocking of Fc receptors was performed using human immunoglobulin ( $3 \mu \mathrm{g} / \mathrm{ml}$; Sigma) and was followed by surface staining. Briefly, cells were stained with fluorescently labeled monoclonal antibodies (mAbs) directed to CD14-BV570 (M5E2, Biolegend, San Diego, CA, USA), CD19-BV570 (HIB19, Biolegend), CD3-BV650 (OKT3, Biolegend), CD4-PerCP-Cy5.5 (SK3, BD), CD8-biotin (RPA-T8, BD), CD45RA-BV605 (HI100, Biolegend), TCR V $\alpha 7.2-\mathrm{PE}$ (3C10, Biolegend), CD103-Alexa-Fluor 488 (Ber-ACT8, Biolegend), CD161-APC (DX12, BD), and CD62L-Alexa Fluor 780 (DREG5 , eBioscience, San Diego, CA, USA) at $4^{\circ} \mathrm{C}$ for $30 \mathrm{~min}$. Staining with streptavidin-QDot800 (Invitrogen) was performed for panels that included biotin-conjugated $\mathrm{mAbs}$ for $30 \mathrm{~min}$ at $4^{\circ} \mathrm{C}$. Cells were then fixed and permeabilized using IC fixation and permeabilization buffers (8222/8333, eBioscience) according to the manufacturer's recommendations. This was followed by intracellular staining with mAbs directed to IL-17A-BV421 (BL168, Biolegend), IFN $\gamma$-PE-Cy7 (B27, BD), TNF $\alpha$-Alexa 700 (MAb11, BD), and CD69-ECD (TP1.55.3, Beckman Coulter, Danvers, MA, USA) which was performed at $4^{\circ} \mathrm{C}$ overnight. After staining, cells were stored in $1 \%$ paraformaldehyde at $4^{\circ} \mathrm{C}$ until data collection. Data were collected using a customized 
LSRII flow cytometer (BD) and then analyzed using the WinList version 7 (Verity Software House, Topsham, ME, USA) software package. Functional responses were considered specific for $H$. pylori-infected autologous macrophages if the differential in the number of positive and negative events between experimental ( $H$. pylori-infected $\mathrm{M} \phi)$ and negative control (uninfected $\mathrm{M} \phi$ ) cultures were significantly increased $(P<0.05)$ using $z$-tests.

\section{Cytotoxic T Lymphocyte Assays}

In vitro-expanded PBMC from volunteers were obtained and used for cytotoxic T lymphocyte (CTL) as previously described for S. typhi (17). Briefly, PBMCs were cocultured with stimulator cells at an effector to stimulator cell ratio of 7:1 in complete RPMI supplemented with $20 \mathrm{IU} / \mathrm{ml}$ of rhIL-2 for 7-8 days. Stimulator cells consisted of THP-1 M $\phi$ infected with $H$. pylori (MOI-20). After infection, THP-1 M $\phi$ were rested overnight and gammairradiated (4,000 rads). For blocking experiments, stimulators were pre-treated for $1 \mathrm{~h}$ with anti-MR1 polyclonal antibodies [10 $\mu \mathrm{g} / \mathrm{ml}$, Santa Cruz Biotechnology (SC), San Diego, CA, USA], or anti-MR1 mAb $(10 \mu \mathrm{g} / \mathrm{ml}$, clone 26.5 , kindly provided by Dr. Ted H. Hansen) or their matched controls $(10 \mu \mathrm{g} / \mathrm{ml})$, goat IgG (Gene Tex Inc, Irvine, CA, USA) and mouse IgG2a (MOPC-173, Biolegend), respectively, before coculture with effector cells. Cytotoxicity was determined by a $4-\mathrm{h}{ }^{51} \mathrm{Cr}$-release assay as previously described (17). Briefly, serial twofold dilutions of expanded effector cells $\left(1.87 \times 10^{4}\right.$ to $1.5 \times 10^{5}$ cells/well $)$ were incubated with $H$. pylori-infected and non-infected $\mathrm{M} \phi$ target cells $\left(3 \times 10^{3}\right.$ cells/well) previously labeled with $200 \mu \mathrm{Ci}$ of ${ }^{51} \mathrm{CrO}_{4} \mathrm{Na}_{2}$ (MP Biomedical, Solon, OH, USA). Cultures were centrifuged at $50 \times g$ for $5 \mathrm{~min}$ and incubated for $4 \mathrm{~h}$ at $37^{\circ} \mathrm{C}$ in the presence of $5 \% \mathrm{CO}_{2}$. Supernatants were then collected and transferred to 96-well plates containing scintillation liquid (OptiPhase; LKB Wallac, Gaithersburg, MD, USA). The amount of ${ }^{51} \mathrm{Cr}$ released was measured with a Wallac Trilux $\beta$-counter (LKB Wallac). Cultures were tested in triplicate wells. The percentage of cytotoxicity was calculated as follows: (experimental release - spontaneous release $) /($ maximal release - spontaneous release $) \times 100$, where spontaneous release is the counts per minute released by target cells in the absence of effector cells and maximal release is the counts per minute released in the presence of $5 \%$ Triton X-100 as previously described (17).

\section{Statistical Analysis}

Data were analyzed using the statistical software GraphPad Prism $^{\mathrm{TM}}$ version 5.03 (Graphpad, San Diego, CA, USA). KruskalWallis ANOVA and Dunn's post-test were used to determine significant differences between multiple groups and to compare selected group pairs. Statistical differences in median values between two groups were determined using Mann-Whitney tests. Correlations between MAIT cell frequencies and age were evaluated using Spearman's tests.

\section{Results}

\section{MAIT Cells are Present in the Stomach}

To evaluate whether MAIT cells are present in the human stomach, we isolated LPMCs from gastric biopsies obtained from various age groups and characterized them by flow cytometry. We then compared the phenotype and function of MAIT cells present in the stomach with those present in the blood. As expected, blood MAIT cells were detected in the three major T-cell subsets $\mathrm{CD}^{+}, \mathrm{CD}^{+}$, and $\mathrm{CD} 4^{-} \mathrm{CD} 8^{-}(\mathrm{DN})$ (Figure 1A; Figure S1 in Supplementary Material). Although at different proportions, gastric MAIT cells were also composed of three different subsets: $\mathrm{CD}^{+}, \mathrm{CD}^{+}$, and DN MAIT cell subsets (Figure 1B; Figure S1 in Supplementary Material). Cumulative data showed that the percentages of gastric $\mathrm{CD}^{+}$ and DN MAIT cell subsets were significantly lower than their counterpart MAIT subsets in blood (Figure 1C). In addition, the percentages of blood and gastric $\mathrm{CD}^{+}$and DN MAIT cell subsets were significantly higher than $\mathrm{CD}^{+}$MAIT subsets (Figure 1C).

Since MAIT cells have been shown to display a T-cell effector memory $\left(\mathrm{T}_{\mathrm{EM}}\right)$ phenotype $(5,12)$, we evaluated the phenotype of blood and gastric MAIT cell subsets by assessing CD45RA and CD62L expression in the two major MAIT cell subsets $\left(\mathrm{CD}^{+}\right.$and DN). Blood MAIT cell subsets showed comparable levels of $\mathrm{T}_{\mathrm{EM}}\left(\mathrm{CD} 2 \mathrm{~L}^{-} \mathrm{CD} 45 \mathrm{RA}^{-}\right)$in $\mathrm{CD}^{+}$and DN MAIT subsets (Figure 1D). Similarly, phenotypic analysis of gastric MAIT cell subsets showed that $\mathrm{CD}^{+}$and DN MAIT subsets displayed similar levels of $\mathrm{T}_{\mathrm{EM}}$ phenotypes ( 70-80\%) (Figure 1E). We then compared blood and gastric MAIT cell subtypes displaying the $\mathrm{T}_{\mathrm{EM}}$ phenotype. We found that gastric LPMCs have significantly higher MAIT cells expressing a $\mathrm{T}_{\mathrm{EM}}$ phenotype than blood in both MAIT subsets (Figure 1F).

Because the presence of MAIT cells in the human gastric mucosa was not previously reported, we determined their frequency in gastric biopsies obtained from children, adults, and the elderly and compared these frequencies to blood MAIT cells. The frequencies of both MAIT cell subsets $\left(\mathrm{CD}^{+}\right.$and $\left.\mathrm{DN}\right)$ in blood were found to be significantly higher in children than in adults and the elderly (Figure 2A). In contrast, in LPMC, although some trends were noted, MAIT cell subsets frequencies were not different among the three age groups (Figure 2B). Using Pearson's regression analysis, we observed a significant inverse correlation $(r=-0.35, P=0.016)$ between the frequency of the CD ${ }^{+}$MAIT subset and age in PBMC but not in LPMC $(r=-0.03, P=0.847)$ (Figures 2C,D). Regression analysis of DN subsets showed similar results, i.e., significant inverse correlations between the frequencies of blood DN ( $r=-0.33, P=0.022)$ MAIT subsets and age (Figure S2A in Supplementary Material). Similar to LPMC CD8 ${ }^{+}$MAIT, DN MAIT subset showed a trend to be correlated $(r=0.25, P=0.10)$ with age (Figure S2B in Supplementary Material).

\section{Activation of Blood MAIT Cells with Live H. pylori or Lysate}

The observation that MAIT cells were present at the gastric mucosa led us to speculate that MAIT cells might play a role in H. pylori infection, a major gastric pathogen. To explore this possibility, we determined the ability of blood MAIT cells from individuals to be activated following exposure to $H$. pylori antigens or live $H$. pylori bacteria by assessing their cytokines/ cytotoxic (IFN- $\gamma$, TNF- $\alpha$, and CD107a) responses. Blood MAIT 

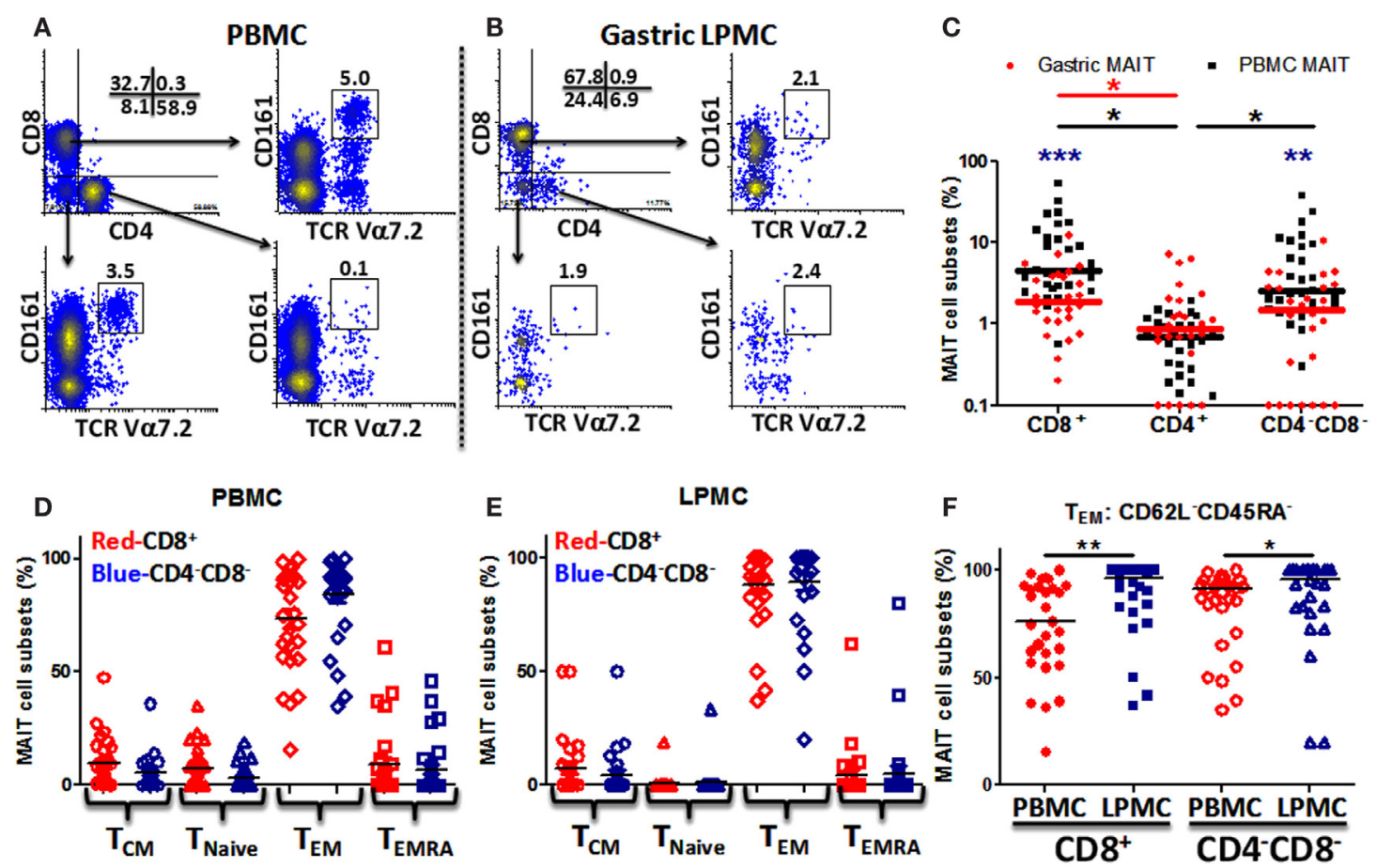

FIGURE 1 | MAIT cells are present in the human gastric mucosa and exhibit T effector memory phenotype. (A) Identification of MAIT cell subsets [CD8+, $\mathrm{CD}^{+}$, and CD4-CD8- (DN)] in PBMC and (B) in gastric LPMC in a representative individual as CD161 ${ }^{\text {hi }}$ TCR V $\alpha 7.2$ (box). (C) Comparison of gastric (red dots; $n=27$ ) and PBMC (black squares; $n=29$ ) MAIT cell subsets. Significant differences between MAIT cell subsets in (i) PBMC [black asterisks ( $\left.{ }^{*}\right)$ ] and (ii) gastric LPMC [red asterisk $\left({ }^{*}\right)$ ]. Blue asterisks $\left(^{*}\right)$ denote significant differences in MAIT cell subsets between PBMC and LPMC. Horizontal lines represent medians (red bars:

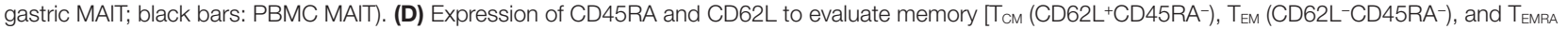
$\left.\left(\mathrm{CD} 62 \mathrm{~L}^{-} \mathrm{CD} 45 \mathrm{RA}{ }^{+}\right)\right]$and $\mathrm{T}_{\text {naive }}\left(\mathrm{CD} 62 \mathrm{~L}^{+} \mathrm{CD} 45 \mathrm{RA}{ }^{+}\right)$subpopulations in MAIT subsets from PBMC $(n=29)$ and $(\mathrm{E}) \mathrm{LPMC}(n=27)$. (F) Comparison of T $\mathrm{EM}$ MAIT cell subsets between PBMC and LPMC. ${ }^{\star} P<0.05 ;{ }^{\star \star} P<0.005 ;{ }^{* \star \star} P<0.0005$.

cells were characterized using the gating strategy described in Figure 1A and Figure S1 in Supplementary Material. While exposure to $H$. pylori antigens (lysate) did not stimulate blood CD8 ${ }^{+}$MAIT cells, exposure of these cells to live $H$. pylori bacteria (MOI of 50) resulted in increased expression of CD107a (5.3\%) and low levels of TNF- $\alpha$ production (0.8\%) (Figure S3A in Supplementary Material). As expected, the positive control, SEB, stimulated CD $8^{+}$MAIT cells to produce high levels of IFN- $\gamma$ and TNF- $\alpha$ and up-regulate CD107a expression, demonstrating that these cells were functional (Figure S3A in Supplementary Material).

\section{Blood CD8+ MAIT Cells Activation by $H$. pylori-Infected Macrophages}

Given the modest response of MAIT cells to live H. pylori stimulation, we explored whether stimulation of blood CD8 ${ }^{+}$ MAIT cells with $H$. pylori-infected macrophages $(\mathrm{M} \phi)$ resulted in increased levels of cell activation. This possibility was supported by previous reports showing that macrophages, B cells, and epithelial cells infected with microbes resulted in higher levels of MAIT cell stimulation $(5,14,23)$. We first optimized the preparation of $H$. pylori-infected targets by infecting THP-1 M $\phi$ with $H$. pylori at different MOI $(10,20,50$, and 100) and evaluating the infection rates in differentiated $\left(\mathrm{CD}^{+} 8^{+}\right)$vs. undifferentiated $\left(\mathrm{CD}^{-} 8^{-}\right) \mathrm{M} \phi$ using an anti-H. pylori antibody and flow cytometry (Figures S3B,C in Supplementary Material). We observed that $H$. pylori were able to infect THP-1 M $\phi$ and the majority of the infected cells were differentiated $\mathrm{M} \phi$ (Figure S3B in Supplementary Material). Of note, although at 50 and $100 \mathrm{MOI}$ the rates of infection showed the highest percentages of $H$. pylori ${ }^{+}$cells, the viability of the $\mathrm{M} \phi$ at these MOI decreased to about 70\% (Figure S3C in Supplementary Material). To further confirm these results, H. pylori-infected M $\phi$ were lysed and plated on agar plates. In agreement with flow cytometric assays, a dose-dependence effect was observed where the infection level was proportional to the H. pylori MOI dose (data not shown). Based on these results, an MOI of 20:1 was chosen for subsequent experiments in the preparation of $H$. pylori-infected $\mathrm{M} \phi$.

To investigate whether blood $\mathrm{CD}^{+}$MAIT cells could be efficiently stimulated by $H$. pylori-infected M $\phi$, MAIT cells (effectors) were exposed to either non-infected $\mathrm{M \phi}$ or $H$. pylori-infected $\mathrm{M} \phi$ (targets) with increasing effector:target (E:T) ratios (5:1, 10:1, 20:1, and 50:1) and cytokine production and CD107a expression measured by flow cytometry. Following stimulation with $H$. pylori-infected THP-1 M $\phi$, higher 

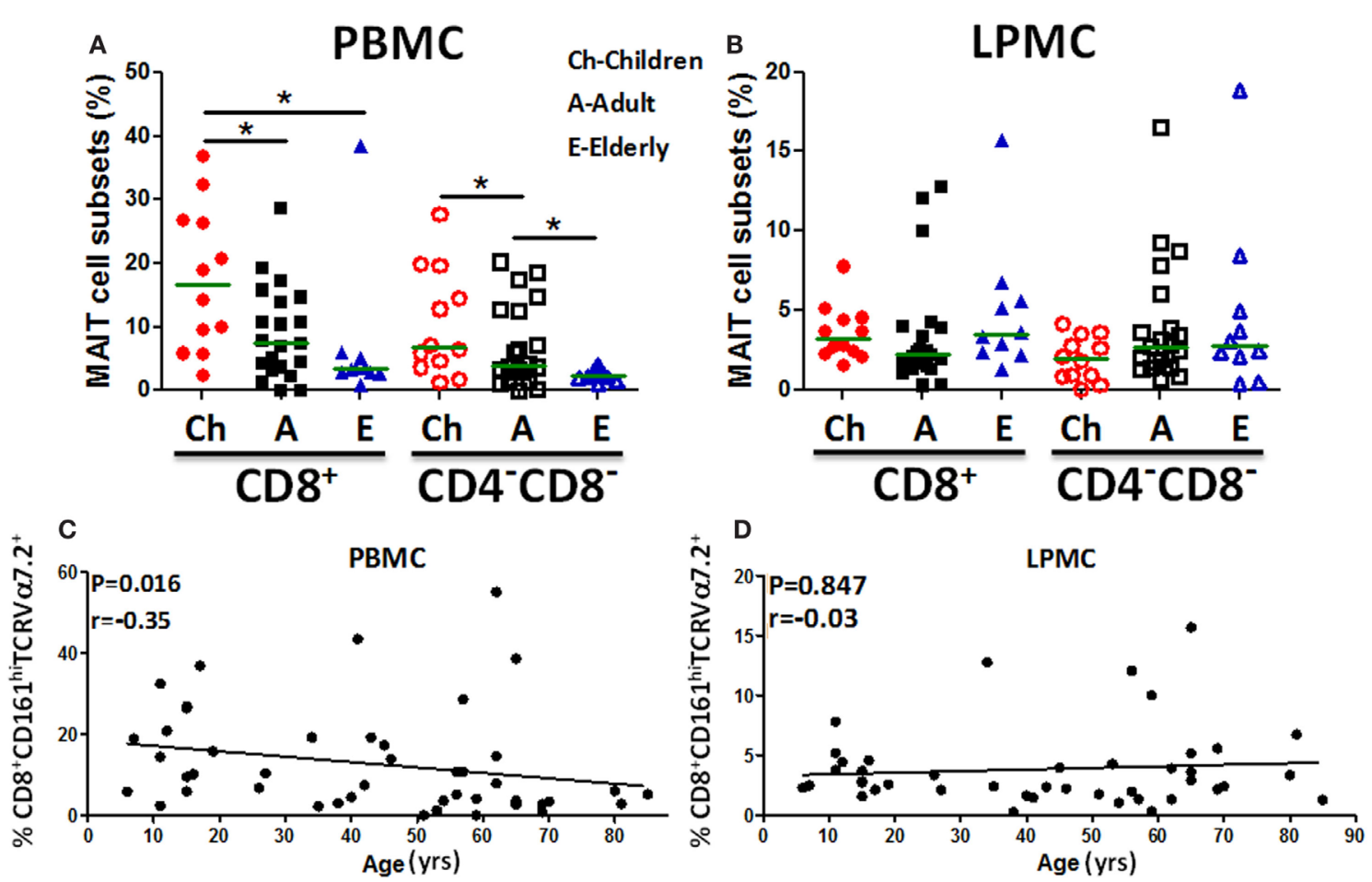

FIGURE 2 | MAIT cells in blood (PBMC) and gastric LPMC in children, adults, and the elderly. (A) PBMC and (B) gastric LPMC obtained from children $(n=12)$, adults $(n=21)$, and the elderly $(n=10)$ were evaluated for the presence of MAIT cells. Significant differences among age groups are denoted by asterisks $\left({ }^{*} P<0.05\right)$. (C) Correlation of CD8 ${ }^{+}$MAIT cells with age in PBMC $(n=46)$ and $(\mathbf{D})$ in gastric LPMC $(n=43)$ was performed using Spearman's correlation analysis. Horizontal green lines in (A,B) represent medians.

percentages of $\mathrm{CD}^{+}$MAIT cells producing cytokines (IFN- $\gamma$, IL-17A, and TNF- $\alpha$ ) and up-regulating expression of CD107a were detected than stimulation with non-infected THP-1 M $\phi$ or effectors (Figure 3A). Cumulative data $(n=11)$ showed that significantly $(P<0.05)$ higher percentages of blood $\mathrm{CD}^{+}$ MAIT cells produced cytokines (IFN- $\gamma$, IL-17A, and TNF- $\alpha$ ) and expressed elevated levels of CD107a following stimulation with $H$. pylori-infected $\mathrm{M} \phi$ than when exposed to non-infected $\mathrm{M} \phi$ (Figures 3B,C).

\section{Blood CD4-CD8- (DN) MAIT Cells Activation by H. pylori-Infected Macrophages}

Given that blood $\mathrm{CD}^{+}$MAIT cells are reactive to $H$. pylori and that MAIT cells were observed in DN, we next investigated whether blood DN MAIT subsets were able to respond to $H$. pylori-infected M $\phi$.

We observed that higher percentages of DN MAIT cells produced cytokines (IFN- $\gamma$, TNF- $\alpha$, and IL-17A) and upregulated CD107a expression following stimulation with $H$. pylori-infected THP-1 M $\phi$ (E:T - 50:1) than when exposed to non-infected $\mathrm{M} \phi$ or when effector cells were cultured alone (Figure 4A). Cumulative data $(n=11)$ showed that significantly higher percentages of DN MAIT cells produced cytokines (IFN- $\gamma$, IL-17, and TNF- $\alpha$ ) and up-regulated CD107a following stimulation with $H$. pylori-infected $\mathrm{M} \phi$ than with non-infected $\mathrm{M} \phi$ (Figure 4B).

\section{Dominant Subsets of Blood MAIT Cells Following Exposure to $H$. pylori-Infected Macrophages}

Since both blood MAIT subsets $\left(\mathrm{CD}^{+}\right.$and $\left.\mathrm{DN}\right)$ were able to recognize and respond to $H$. pylori-infected THP-1 M $\phi$, we then examined whether there were differences in the activation levels and quality of the responses between these subsets. Following stimulation with $H$. pylori-infected THP-1 M $\phi$, increased expression of the activation marker CD69 was observed in both MAIT subsets compared with non-infected $\mathrm{M} \phi$ (Figure 4C). Interestingly, both MAIT subsets exhibited similar percentages of $\mathrm{CD}^{+} 9^{+}$cells (Figure 4C), indicating that $\mathrm{CD}^{+}$and DN MAIT subsets are similarly activated by $H$. pylori-infected macrophages. However, further analysis of $\mathrm{CD}^{2} 9^{+}$MAIT cells indicated that although $\mathrm{CD}^{+}$and $\mathrm{DN}$ are equally activated (based on similar $\mathrm{CD} 69^{+}$expression levels), significantly higher percentages of $\mathrm{CD}^{+}$MAIT cells produced cytokines (IFN- $\gamma$, TNF- $\alpha$, and IL-17A) and up-regulated CD107a than DN MAIT cells (Figure 4C). Thus, the cytokine responses and CD107a expression to $H$. pylori-infected THP-1 M $\phi$ are dominated by the $\mathrm{CD}^{+}$MAIT subset ( $>60 \%$ ) (Figure $4 \mathrm{C}$ ).

\section{Multifunctional MAIT Cell Responses Following Exposure to $H$. pylori-Infected Macrophages}

Our group has previously shown that MAIT cells can respond to $S$. typhi by secreting multiple cytokines simultaneously (14). Thus, we next investigated the multifunctionality of the responses 


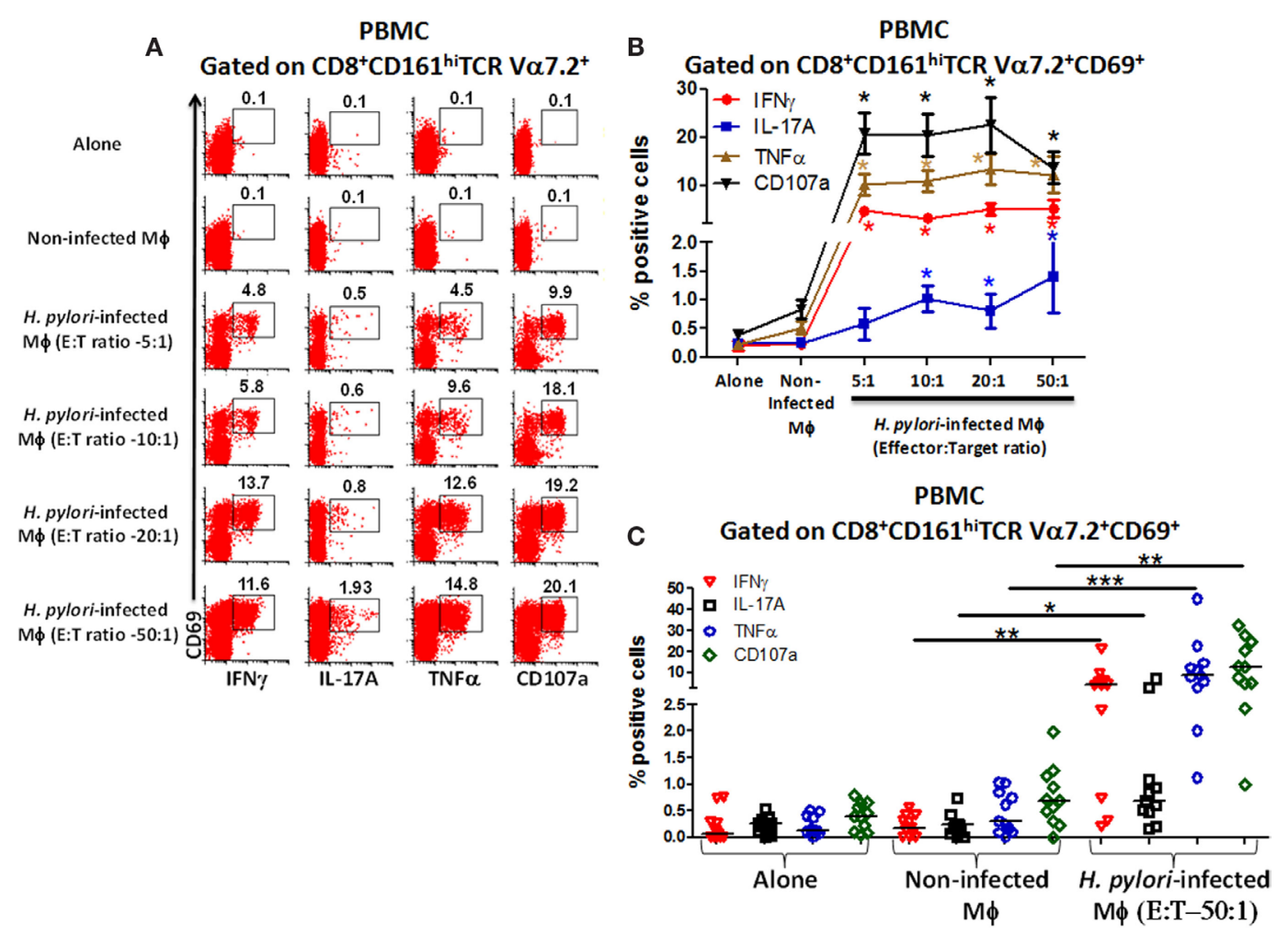

FIGURE 3 | Responses of blood CD8+ MAIT cells from healthy adults to $\boldsymbol{H}$. pylori-infected macrophages. (A) Representative volunteer showing the induction of cytokine production (IFN- $\gamma$, TNF- $\alpha$, IL-17A) and up-regulation of CD107a expression by CD8+ MAIT cells following stimulation by H. pylori-infected differentiated THP-1 macrophages (M $\phi)$ at increasing effector to target (E:T) ratios $(5: 1,10: 1,20: 1,50: 1)$. (B) Cumulative data $(n=11)$ displaying the percentages of

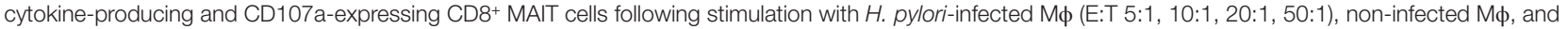
effector cells alone. Shown are significant differences $\left(^{*}\right)$ between non-infected and infected targets. Significances were $P<0.0005$ for CD107 and TNF- $\alpha$ and $P<0.005$ for IFN- $\gamma$ at all E:T ratios and $P<0.05$ for IL-17A at 10:1, 20:1, and 50:1 E:T ratios. (C) Cumulative data ( $n=11)$ showing cytokine production and

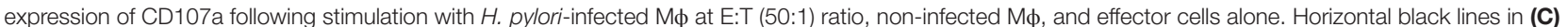
represent medians. Significant differences were determined between non-infected and $H$. pylori-infected $\mathrm{M \phi}\left({ }^{\star} P<0.05 ;{ }^{* \star} P<0.005 ;{ }^{\star \star \star} P<0.0005\right)$.

exhibited by blood CD8 ${ }^{+}$MAIT cells against $H$. pylori-infected differentiated THP-1 macrophages. Analysis of multiple cytokines (IFN- $\gamma$, TNF- $\alpha$, and IL-17A) and/or CD107 expression patterns (16 possible combinations) using the Winlist FCOM function revealed that MAIT cell responses were characterized by single, double, or triple cytokine producers/CD107 expressors, albeit at different percentages, following stimulation with $H$. pyloriinfected THP-1 M $\phi$ (Figure 5A). Interestingly, $\mathrm{CD}^{+} \mathrm{MAIT}$ cells produced IL-17A mostly as single-cytokine-producing cell following stimulation with $H$. pylori-infected $\mathrm{M} \phi$. In contrast, $\mathrm{CD}^{+}$MAIT cells response to $H$. pylori-infected $\mathrm{M} \phi$ produced IFN- $\gamma$ mostly as multifunctional [triple-positive cells (IFN- $\gamma^{+}$ TNF- $\alpha^{+}$CD107a $\mathrm{a}^{+}$) (Figure 5A). We also noted that the cytotoxic marker, CD107a, was prominent in both multifunctional and single-positive cell subsets, suggesting that MAIT cells are highly cytotoxic to $H$. pylori-infected THP-1 M $\phi$.

\section{MAIT Cells Are Cytotoxic to H. pylori-Infected Macrophages}

Because we observed a preponderance of the cytotoxic degranulation marker CD107a (LAMP-1) expressed on stimulated MAIT cells, we directly explored the functional cytotoxic ability of MAIT cells to kill $H$. pylori-infected targets using standard chromium $\left({ }^{51} \mathrm{Cr}\right)$ release assays. We observed significant increases in target cell killing in cultures containing $H$. pylori-infected THP-1 M $\phi$ when compared to cultures with non-infected THP-1 M $\phi$ (Figure 5B). To assess whether this MAIT cell killing involved MR1-restriction, we treated the stimulator cells with anti-human MR1 antibodies or matched immunoglobulin or isotype controls to block the lysis of $H$. pylori-infected THP-1 $\mathrm{M} \phi$ (Figures 5B,C). We observed that blocking of MR-1 using either a goat polyclonal (Figure 5B) or a mouse anti-human monoclonal (clone 26.5; Figure 5C) antibodies resulted in significant decreases in the lysis of $H$. pylori-infected THP-1 $\mathrm{M} \phi$ when compared to cultures with $H$. pylori-infected targets (Figures 5B,C). However, the $26.5 \mathrm{mAb}$ to MR1 was more effective in preventing lysis of $H$. pylori targets than the polyclonal goat MR1 antibody (Figures 5B,C). As expected, addition of matched immunoglobulin (IgC) or isotype (IC) controls failed to decrease the lysis of $H$. pylori-infected $\mathrm{M} \phi$ observed in cultures exposed to $H$. pylori-infected targets (Figures 5B,C). These results confirmed that blood MAIT cells exhibit a cytotoxic 


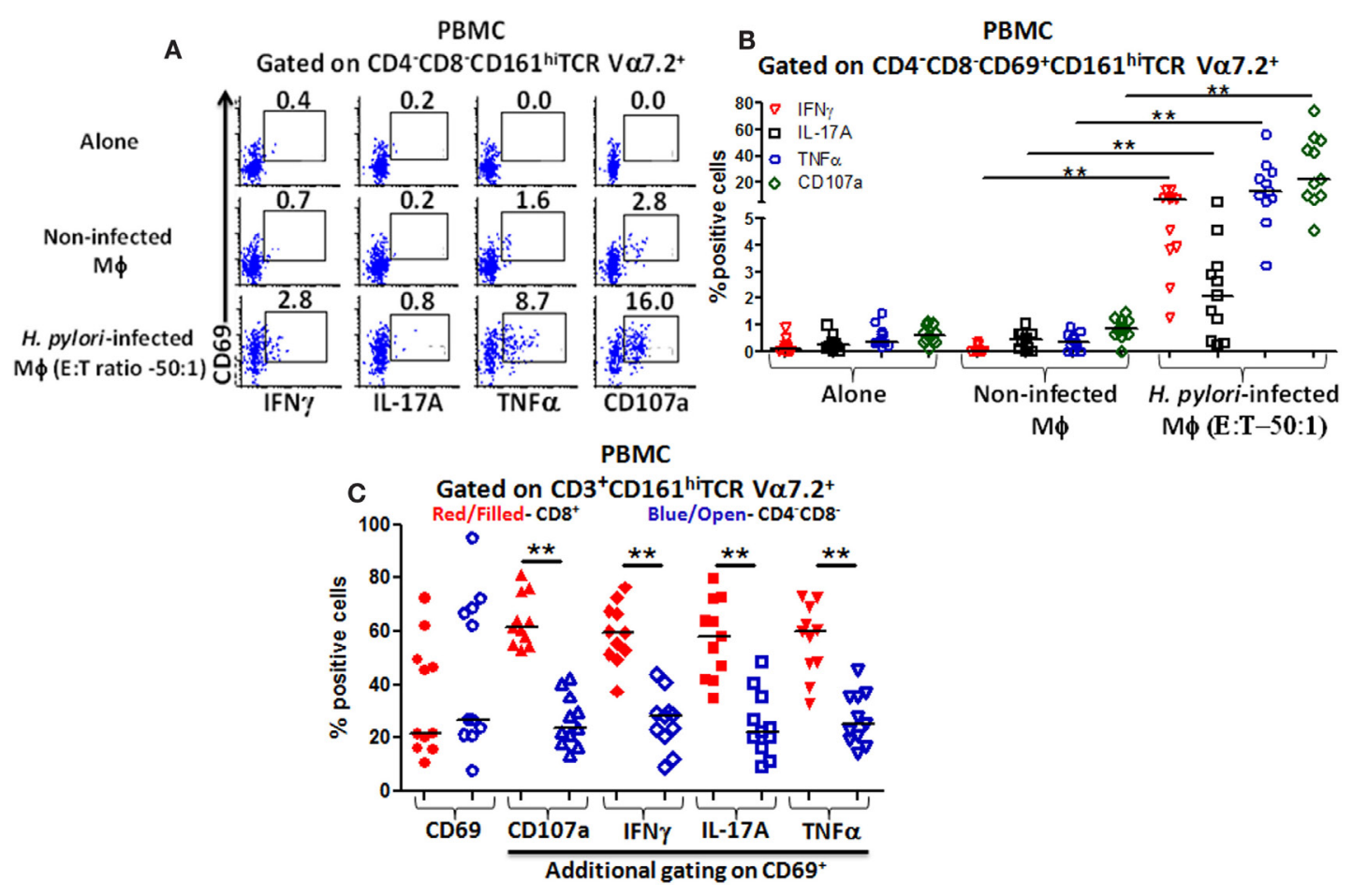

FIGURE 4 | Responses of blood CD4-CD8- (DN) MAIT subsets from healthy adults to $\boldsymbol{H}$. pylori-infected macrophages. (A) Representative volunteer showing the induction of cytokine production (IFN- $\gamma$, TNF- $\alpha, I L-17 A$ ) and up-regulation of CD107a expression in DN MAIT cells following stimulation with media (alone), non-infected THP-1 macrophages (M $\phi)$, or H. pylori-infected THP-1 M $(E: T-50: 1)$. (B) Cumulative data $(n=11)$ showing production of cytokines (IFN- $\gamma$, TNF- $\alpha$, and IL-17A) and expression of CD107a by DN MAIT cells following stimulation with $H$. pylori-infected THP-1 M $(\mathrm{E}: \mathrm{T}-50: 1)$. (C) CD69 up-regulation by

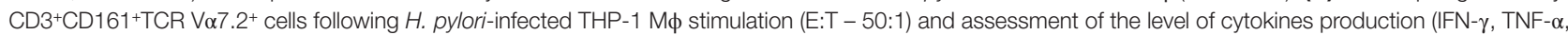
$\mathrm{IL}-17 \mathrm{~A})$ and CD107a expression in CD69+ MAIT cell subsets (CD8 ${ }^{+}$and CD4-CD8-) following stimulation with H. pylori-infected THP-1 Mp (E:T - 50:1) $(n=11)$. Horizontal black lines in $\mathbf{( B , C )}$ represent medians. Significant differences are denoted by asterisks $\left({ }^{\star \star} P<0.005\right)$.

effector function to $H$. pylori-infected THP-1 M $\phi$ cells and that this effect is MR-1 restricted.

\section{MAIT Cell Subsets (CD8+and CD4-CD8- DN) Responses to $H$. pylori-Infected Primary Autologous Macrophages Are MR-1 Restricted}

Given that MAIT cells detect bacterially derived antigens presented by the MHC-like molecule MR-1, we next investigated whether responses to $H$. pylori-infected human primary autologous macrophages by $\mathrm{CD}^{+}$and DN MAIT cell subsets were MR-1 restricted. To address this question, $H$. pylori-infected primary autologous macrophages were incubated with neutralizing antihuman MR-1 antibodies or matched isotype controls to block the cytokine responses (IFN- $\gamma$ and TNF- $\alpha$ ) and/or expression of CD107a elicited in MAIT cells subsets. We observed that blocking of MR-1 using a mouse anti-human monoclonal antibody (clone 26.5; Figure 6A) resulted in significantly decreased production of cytokines (IFN- $\gamma$ and TNF- $\alpha$ ) and expression of CD107a by $\mathrm{CD}^{+}$(Figure 6A) and DN MAIT cell subsets (Figure 6B) when compared to cultures with $H$. pylori-infected autologous targets only. In contrast, the addition of a matched isotype (IC) control failed to significantly decrease the production of cytokines and expression of $\mathrm{CD} 107$ by $\mathrm{CD}^{+}$(Figure $\left.6 \mathrm{~A}\right)$ or $\mathrm{DN}\left(\mathrm{CD} 4^{-} \mathrm{CD} 8^{-}\right)$ (Figure 6B) MAIT cells recorded in cultures exposed to $H$. pylori-infected autologous targets. Cumulative data $(n=5)$ showed significant suppression in the production of cytokines (IFN- $\gamma$ and TNF- $\alpha$ ) and expression of CD107 by both MAIT cells subsets $\left(\mathrm{CD}^{+}\right.$and $\left.\mathrm{DN}\right)$ following blocking with MR-1 antibody but not with a matched isotype control (Figures 6C,D). These results indicate that both MAIT cell subsets detect and respond to $H$. pylori-infected primary autologous macrophages and that this effect is MR-1 restricted.

\section{Gastric MAIT Cells Activation by H. pylori- Infected Macrophages}

Next, we investigated whether gastric MAIT cells would recapitulate the immune responses observed in blood MAIT cells against H. pylori-infected THP-1 M $\phi$. To address this question, isolated gastric LPMCs were stimulated with $H$. pylori-infected THP-1 $\mathrm{M} \phi$, non-infected THP-1 M $\phi$, anti-CD3/CD28 beads (positive control), or media (negative control). Following stimulation with H. pylori-infected $\mathrm{M} \phi$, higher percentages of gastric $\mathrm{CD} 8^{+} \mathrm{MAIT}$ cells produced cytokines (IFN- $\gamma$ and TNF- $\alpha$ ) and up-regulated CD107a when compared to the levels following exposure to non-infected $\mathrm{M} \phi$ or cells alone (cytograms from a representative subject are shown in Figure 7A). Cumulative data $(n=8)$ showed that significantly higher percentages of gastric $\mathrm{CD} 8^{+}$MAIT cells produced IFN- $\gamma(5.8 \pm 1.8 \%$; mean \pm SE; Figure $7 B)$, TNF- $\alpha$ 


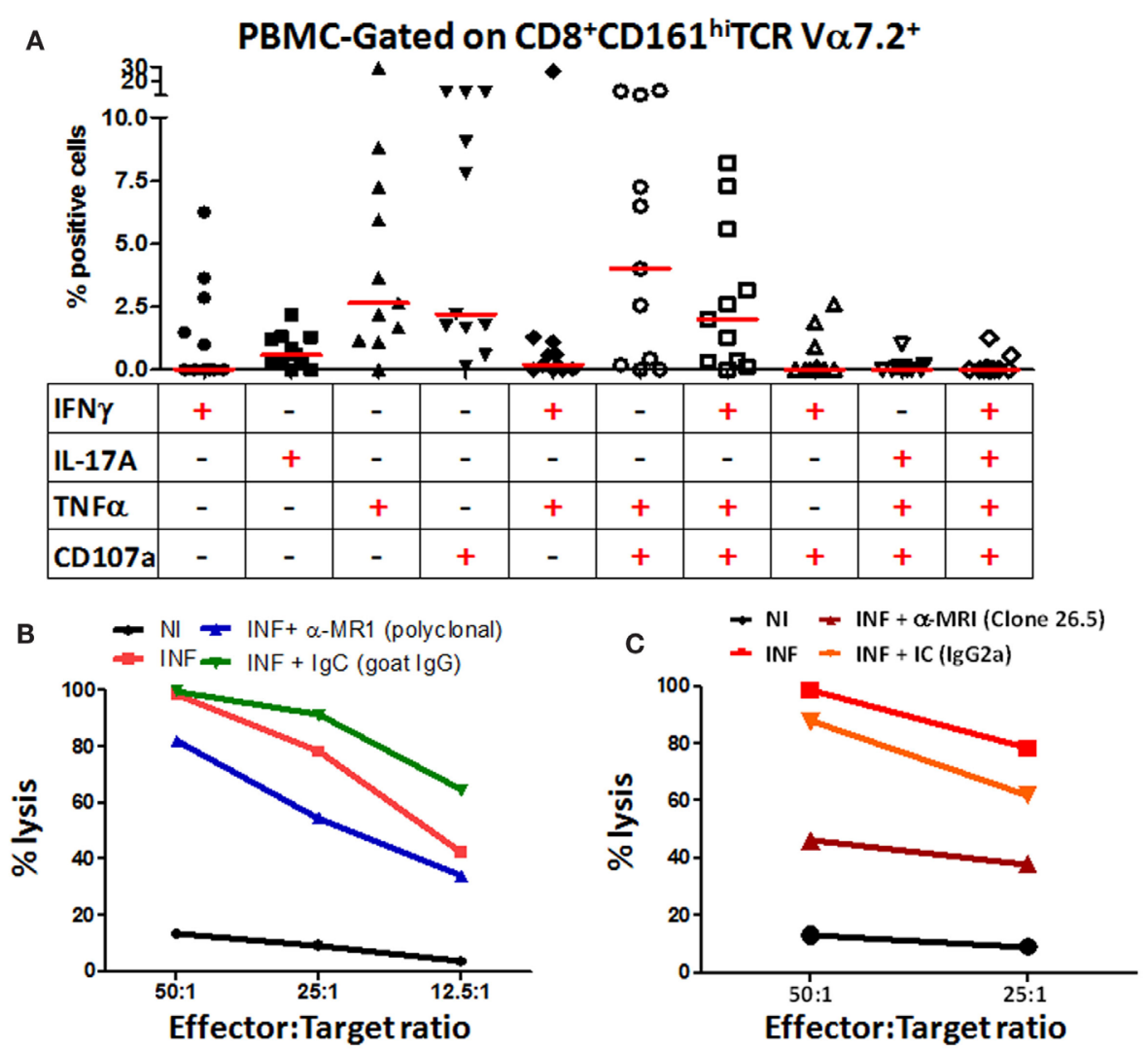

FIGURE 5 | Blood MAIT cells from healthy adults exhibit multifunctional abilities and are cytotoxic to $\boldsymbol{H}$. pylori-infected macrophages. (A) Multifunctional activities of MAIT cells were determined by simultaneous detection of three intracellular cytokines (IFN- $\gamma$, TNF- $\alpha$, and IL-17A) and expression of CD107a by CD8+ MAIT cells following stimulation with H. pylori-infected THP-1 Mф (E:T - 50:1). Scatter plot shows single-cytokine-producing and CD107expressing cells and the six predominant multi-cytokine-producing/CD107-expressing patterns using PBMCs from healthy adult volunteers. Horizontal red lines indicate the median responses. Multifunctionality was analyzed using the FCOM feature of WinList. (B) H. pylori CTL responses by MAIT cells were measured at various effector:target ratios (50:1, 25:1, 12.5:1, 6.25:1) in non-infected (NI) and H. pylori-infected (INF) THP-1 M申. Blocking of CTL responses was performed using anti-human MR-1 antibody (goat, polyclonal) $(10 \mu \mathrm{g} / \mathrm{ml}$ ) or goat lgG control (immunoglobulin control; lgC; $10 \mu \mathrm{g} / \mathrm{ml})$. (C) H. pylori CTL responses by MAIT cells were measured at two effector:target ratios (50:1 and 25:1) in NI and INF THP-1 Mф. Blocking of CTL responses were performed using the anti-human MR-1 mAb (clone 26.5) $(10 \mu \mathrm{g} / \mathrm{ml})$ or a matched isotype control (IC, $10 \mu \mathrm{g} / \mathrm{ml})$. Lines show the mean percentages of cytotoxicity at different $\mathrm{E} / \mathrm{T}$ ratios from triplicate wells. The data are representative of four separate experiments.

$(8.5 \pm 2.1 \%$; mean \pm SE; Figure 7C), and up-regulated CD107a $(8.2 \pm 1.0 \%$; mean \pm SE; Figure $7 \mathrm{D})$ following stimulation with $H$. pylori-infected THP-1 M $\phi$ compared to non-infected М $\phi$. A trend, albeit not significant, was also observed for IL-17 production (Figure 7B). We also determined the percentage of responders, i.e., volunteers who exhibited significantly increased responses (determined by $z$-tests based on the number of events collected) in the presence of gastric MAIT cells stimulated with H. pylori-infected THP-1 M $\phi$ compared to uninfected M $\phi$ (Figure S4 in Supplementary Material). We observed 87.5, 75, and $100 \%$ responders for IFN- $\gamma$, TNF- $\alpha$, and CD107a expression, respectively (Figure S4 in Supplementary Material).

\section{MAIT Cells Are Lower in PBMC of H. pylori-Infected Volunteers}

Because MAIT cells in both blood and gastric mucosa were found to be reactive to $H$. pylori-infected $\mathrm{M} \phi$, we speculated that there might be differences between MAIT cell frequencies between
H. pylori-infected $\left(\mathrm{Hp}^{+\mathrm{ve}}\right)$ and uninfected $\left(\mathrm{Hp}^{-\mathrm{ve}}\right)$ volunteers. To explore this possibility, we assessed the frequency of MAIT cells in PBMC and gastric LPMC obtained from $\mathrm{Hp}^{\text {+ve }}$ and $\mathrm{Hp}^{-v e}$ volunteers. We observed significant decreases in the frequency of $\mathrm{CD}^{+}$MAIT cells in blood of $\mathrm{Hp}^{+\mathrm{ve}}$ compared with $\mathrm{Hp}^{-\mathrm{ve}}$ volunteers (Figure 8A). Analysis of the DN MAIT subsets revealed significant decreases in the frequencies of PBMC DN MAIT cells in $\mathrm{Hp}^{+\mathrm{ve}}$ when compared with $\mathrm{Hp}^{-\mathrm{ve}}$ volunteers (Figure 8A ). These results indicated that decreased levels of $\mathrm{CD}^{+}$and $\mathrm{DN}$ MAIT cell subsets are present in blood during $H$. pylori infection. We then determined the frequency of MAIT cells in the gastric mucosa for the same $\mathrm{Hp}^{+\mathrm{ve}}$ and $\mathrm{Hp}^{-\mathrm{ve}}$ volunteers. Interestingly, no statistically significant differences were observed among the LPMC MAIT cell subset frequencies in gastric biopsies obtained from $\mathrm{Hp}^{\text {+ve }}$ and $\mathrm{Hp}^{-v e}$ groups (Figure 8B). Since our results suggest that MAIT cells in the gastric mucosa are relatively constant during aging and infection, we hypothesized that these gastric MAIT cells might represent populations of tissue-resident 

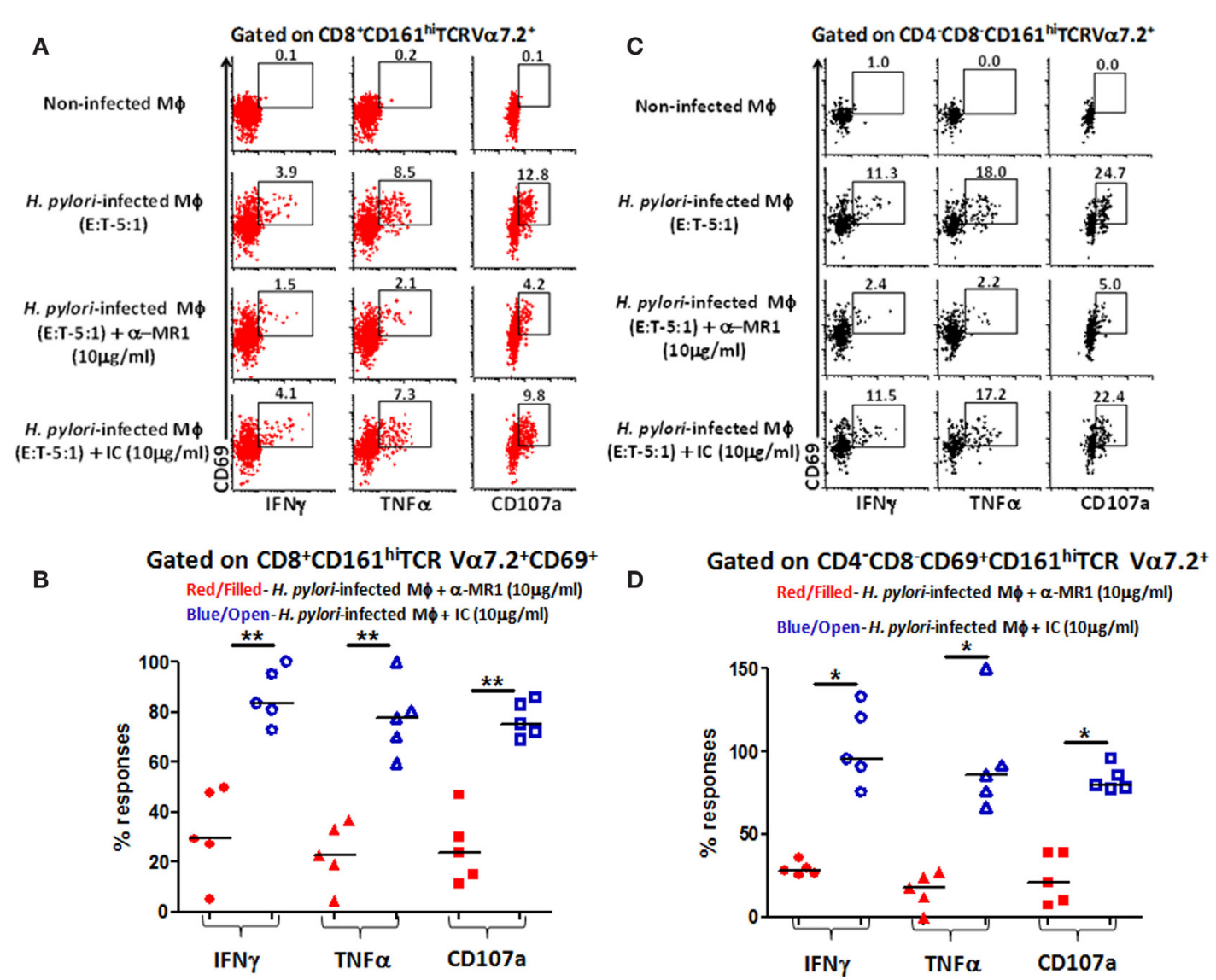

FIGURE 6 | MR1 restriction of responses by blood MAIT CD8 ${ }^{+}$and CD4-CD8- DN subsets from healthy adults to $\mathrm{H}_{\text {. pylori-infected primary }}$ autologous macrophages. Representative volunteer showing the induction of cytokine production (IFN- $\gamma$ and TNF- $\alpha$ ) and up-regulation of CD107a expression in

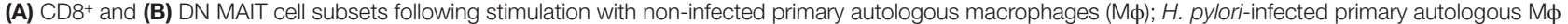

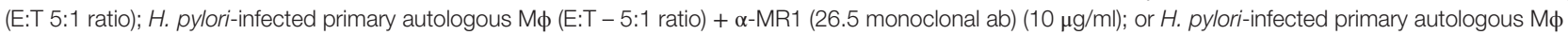
$\left(\mathrm{E}: \mathrm{T}-5: 1\right.$ ratio) + isotype control $(10 \mu \mathrm{g} / \mathrm{ml})$. Cumulative data $(n=5)$ showing MR1-restricted production of IFN- $\gamma$, TNF- $\alpha$, and expression of CD107a by (C) CD8 ${ }^{+}$ and (D) DN MAIT cells following stimulation with the four treatments described above. The \% of responses compared to media control (\% of media control) was calculated as (cytokine production/CD107 expression in cells stimulated with H. pylori-infected primary autologous macrophages containing either $\alpha$-MR1 or IC)/ (cytokine production/CD107 expression in cells stimulated with H. pylori-infected primary macrophages) $\times 100$. Horizontal black lines in (B,D) represent medians. Significant differences are denoted by asterisks $\left({ }^{*} P<0.05 ;{ }^{* \star} P<0.005\right)$.

cells $\left(\mathrm{T}_{\mathrm{R}}\right)$. To explore this possibility, we assessed the hallmark markers of tissue-resident cells, i.e., expression of CD103 and CD69, on gastric LPMC and blood MAIT cells. We observed that

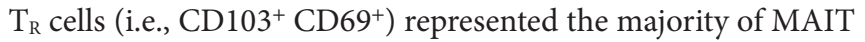
cells in gastric LPMC, but only a small proportion in PBMC (Figures 8C,D).

\section{Discussion}

Mucosal-associated invariant $\mathrm{T}$ cells are a class of innate $\mathrm{T}$ cells widely believed to provide immediate effector functions in response to infections in human tissues $(5,24)$. Here, we described, for the first time, the presence of MAIT cells in the human gastric mucosa of children, adults, and the elderly and characterized their reactivity to $H$. pylori.

Recent reports indicate a broad distribution of MAIT cells in the human body. Human MAIT cells comprise $1-10 \%$ of total T cells in peripheral blood and in lungs (13,25), 15-39\% in liver (26), and $3-5 \%$ in intestine (5). Here, we reported that the frequency of MAIT cells present in the gastric mucosa range between 0.1 and $12 \%$. Interestingly, we observed significantly higher percentages of MAIT cells expressing a classical $\mathrm{T}_{\mathrm{EM}}$ phenotype in the gastric mucosa than in peripheral blood. These results suggest that the gastric MAIT cells have the capacity to act as innate effectors for pathogens in the stomach microenvironment.

We also assessed the percentages of MAIT in peripheral blood and gastric LPMC from children, adults, and the elderly. These assessments are particularly important since few studies have compared MAIT cell frequencies among various age groups. Interestingly, we observed significantly higher percentages of MAIT cells in the blood of children when compared with those observed in adults and the elderly. Furthermore, we demonstrate that the percentages of $\mathrm{CD}^{+}$and DN MAIT subsets in peripheral blood are inversely correlated with age. These observations extend 


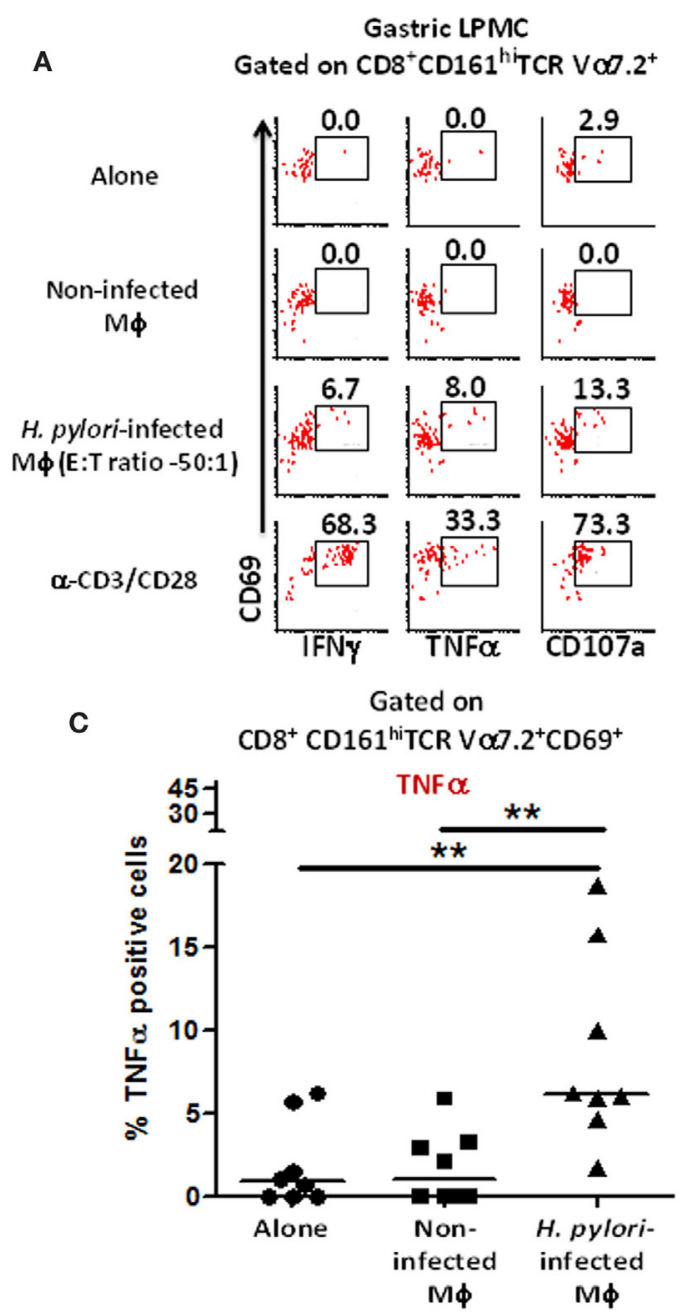

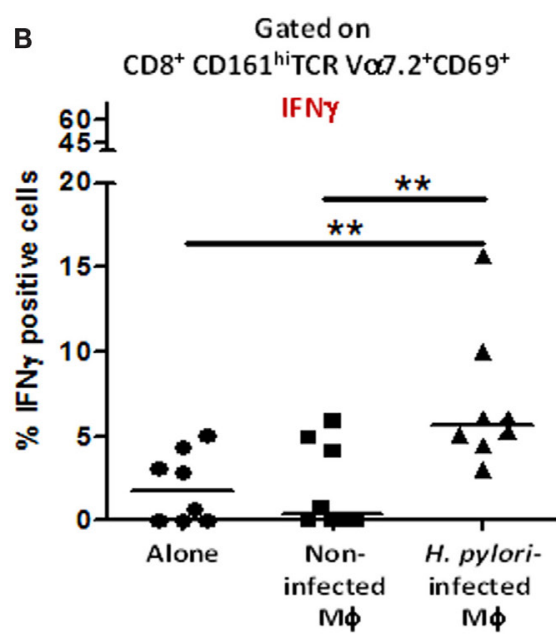

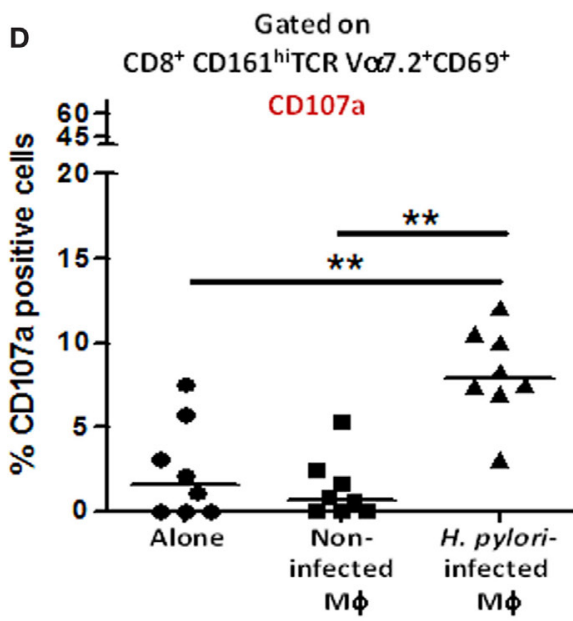

FIGURE 7 | Responses of human gastric MAIT cells to $\boldsymbol{H}$. pylori-infected macrophages. (A) Representative volunteer showing the induction of cytokine production (IFN- $\gamma$, TNF- $\alpha$ ) and expression of CD107a by gastric CD8 ${ }^{+}$MAIT following stimulation by $H$. pylori-infected and non-infected THP-1 M $\phi$. Shown are cumulative data $(n=8)$ of (B) IFN- $\gamma$ production, (C) TNF- $\alpha$ production, and (D) expression of CD107a by CD8 ${ }^{+}$MAIT following stimulation by $H$. pylori-infected M $\phi$ and non-infected THP-1 Mф. Horizontal lines in (B-D) represent medians. Significant differences are denoted by ${ }^{* \star} P<0.005$.

those reported in very recent studies, which showed that MAIT cell frequencies were significantly lower in PBMCs obtained from elderly volunteers than in young adult volunteers $(27,28)$.

These results raise an important question: what is the role of MAIT cells in children during infections (e.g., H. pylori)? Epidemiological studies have indicated that children infected with $H$. pylori usually develop mild $H$. pylori-associated gastritis but only rarely peptic ulcer or gastric atrophy $(29,30)$. Based on our observations in PBMC, it is reasonable to speculate that the higher percentages of MAIT cell in children might be associated with protection from severe disease. However, the dichotomy observed in the percentages of MAIT cells, which differ among age groups when measured in peripheral blood but not in the gastric mucosa, suggests that caution has to be exercised when interpreting data solely derived from circulating MAIT cells. The likelihood that differences exist between MAIT cells in PBMC and in the gastric mucosal is supported by our results showing that the majority of gastric MAIT cells (>80\%) express tissueresident markers $\left(\mathrm{CD} 69^{+} \mathrm{CD} 103^{+}\right)$, which are absent in $\mathrm{PBMC}$ MAIT. Additional studies to evaluate in detail the phenotype and function of MAIT cells in circulation and in the gastric mucosa are needed to conclusively establish the role of these MAIT cells in response to $H$. pylori infection.

The study of host immunological responses to $H$. pylori is a field of intense research (15). Following $H$. pylori colonization of the gastric mucosa, there is a significant influx of immune cells into the LP, including macrophages, dendritic cells (DCs), $\mathrm{B}$ cells, neutrophils, and T cells, which modulate the immunological microenvironment toward a Th1-type response $(31,32)$. Interestingly, these studies found an abundance of $\mathrm{T}$ cells in the antrum of $H$. pylori-infected donors (33). The present study is the first to describe the interactions between peripheral blood and gastric MAIT cells with $H$. pylori. We observed that MAIT from both tissues reacted to $H$. pylori by producing Th 1 (TNF- $\alpha$, IFN- $\gamma$ ) 


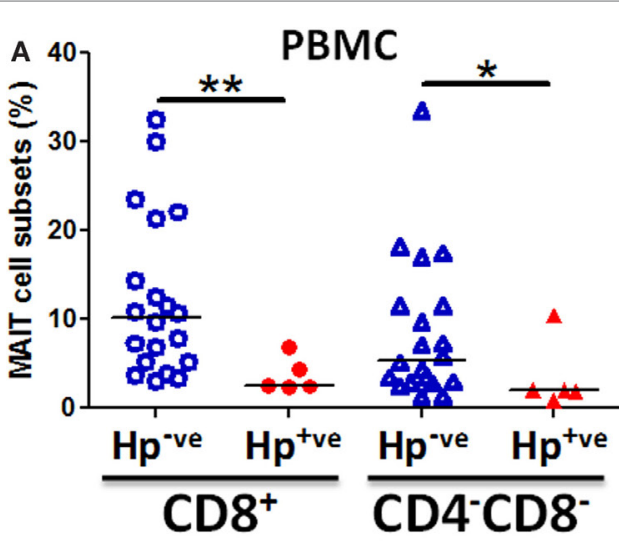

C

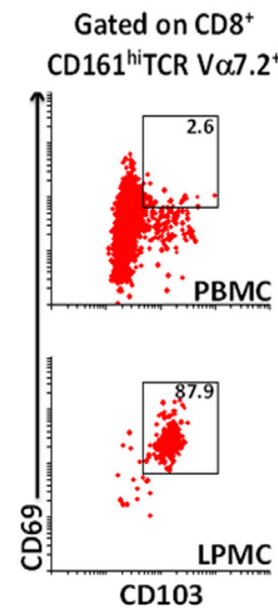

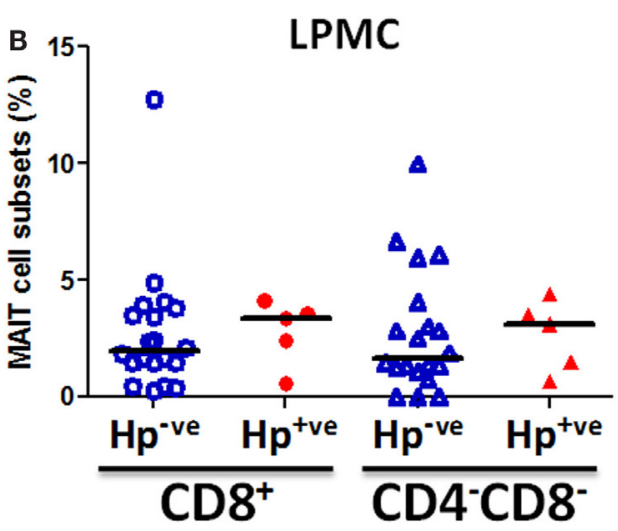

D

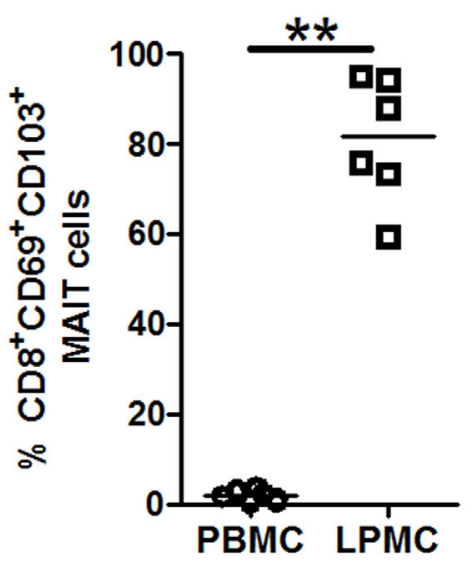

FIGURE 8 | MAIT cells are lower in blood but not in the gastric mucosa of $\boldsymbol{H}$. pylori-infected volunteers. Aggregate data of the percentages of MAIT cell

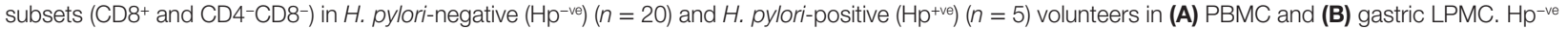
volunteers were age-matched to $\mathrm{Hp}^{+v e}$ volunteers. (C) Representative example of tissue-resident T markers (CD69 and CD103) expression on CD8 ${ }^{+}$MAIT cells from PBMC and gastric LPMC. (D) Cumulative data $(n=6)$ comparing the expression of $T_{R}$ MAIT cells in PBMC and LPMC. Horizontal lines in (A,B,D) represent medians. Significant differences are denoted by asterisks $\left({ }^{\star} P<0.05,{ }^{\star \star} P<0.005\right)$.

and $\mathrm{T}_{\mathrm{H}} 17$ (IL-17A) cytokines as well as acquiring cytotoxic effector function (expression of CD107a and lysis of H. pylori-infected $\mathrm{M \phi )}$. Classical T cells have been implicated in the modulation of the gastric mucosa toward Th1- and Th17-type responses following $H$. pylori infection $(32,34)$. Here, we show that MAIT cells are also able to produce these proinflammatory cytokines following H. pylori stimulation. These observations suggest that MAIT cells are likely to play an important role in contributing to establish a Th1/Th17-type environment in the human gastric mucosa during H. pylori infection.

A key question that remains unanswered is whether MAIT cells are protective or enhance the pathogenicity of $H$. pylori infection. We hypothesize that MAIT cells may likely play an essential role in eliminating the bacteria due to its ability to produce high levels of Th 1 cytokines (associated with protection) and being cytotoxic. Of note, we observed that a small fraction of MAIT cells have multifunctional capability against $H$. pylori-infected cells. These cells, which are able to produce simultaneously IFN- $\gamma$ and TNF$\alpha$ and exhibit cytotoxic effector functions, might be particularly effective in controlling $H$. pylori infection. In the present study, we show, using two complementary approaches, that MAIT cells have cytotoxic capabilities against $H$. pylori-infected cells. Although following $H$. pylori colonization, the bacteria usually reside in the mucus layer outside the gastric mucosa, it has been recently shown that the bacteria can infect epithelial cells and LPMC becoming a facultative intracellular bacteria (35), and a recent report has shown that MAIT cells can lyse bacterially infected epithelial cells (23). Thus, lysis of $H$. pylori-infected cells by MAIT cells could serve as a bridge between innate and classical T cells by eliminating $H$. pylori-infected cells soon after infection. Future studies directed to address MAIT cell responses to $H$. pylori-infected cells in $H$. pylori-infected and non-infected individuals, both systemically and in the gastric microenvironment, will be required to determine the precise role of MAIT cells in $H$. pylori infection.

It has recently been shown that products of the riboflavin metabolic pathway lead to MAIT cell activation. For example, 5 amino-6-D-ribitylaminouracil (5-A-RU) after non-enzymatic condensation with glyoxal or methylglyoxal results in the formation of 5-(2-oxopropylideneamino)-6-D-ribitylaminouracil 
(5-OP-RU), which is an unstable intermediate captured by MR-1 resulting in MAIT cell activation (36). However, it has been suggested that different bacteria might activate MAIT cells through other ligands (37). Moreover, various factors such as virulence factors, location of pathogen (e.g., intracellular), and type of APCs may also influence the response of MAIT cells to defined pathogens (38). However, since $H$. pylori express genes of the riboflavin metabolic pathway, it is likely that MAIT cells activation by $H$. pylori results, at least in part, from products of the riboflavin operon.

Another interesting observation in the present study is that the percentages of MAIT cells in PBMC of individuals infected with $H$. pylori $\left(\mathrm{Hp}^{+\mathrm{ve}}\right)$ are significantly decreased as compared to those from uninfected $\left(\mathrm{Hp}^{-\mathrm{ve}}\right)$ individuals. These results are in agreement with those observed in individuals with other active infections. For example, Le Bourhis et al. observed significantly lower proportions of MAIT cells in the blood of patients with pulmonary bacterial pathologies, including tuberculosis (4). Likewise, Gold et al. demonstrated that $M$. tuberculosis (Mtb)-reactive MAIT were decreased in PBMC but enriched in human lungs (13). These observations further support the existence of a dichotomy between MAIT cells present in peripheral blood and those in peripheral tissues. This is an important consideration since, largely due to the difficulty in obtaining peripheral tissues in humans, the interpretation of what might constitute a protective immune response is based largely on observations derived from studying peripheral blood. Our results showing decreased levels of MAIT cells in circulation suggest that these cells may have left peripheral blood to infiltrate gastric tissues after $H$. pylori infection. To address this hypothesis, we determined the percentages of MAIT cells in circulation and in the gastric mucosa of individual $H$. pylori-positive volunteers. No statistically significant differences were observed in the percentages of MAIT cells in the gastric mucosa of healthy and $H$. pylori-infected volunteers. Furthermore, we showed that the majority of gastric MAIT cells ( $>80 \%)$ express markers $\left(\mathrm{CD} 69^{+} \mathrm{CD} 103^{+}\right)$compatible with tissue-resident cells, suggesting that MAIT cells can acquire a tissue-resident-like phenotype at the gastric mucosa and therefore likely to be ready to respond quickly following exposure to enteric pathogens.

Regarding the existence of multiple MAIT subsets, Gold and Lewinsohn observed that only $\mathrm{CD}^{+}$but not DN MAIT cell subsets were reactive to $M$. tuberculosis (1). Moreover, Dusseaux et al. noted that there is no evidence (phenotypic or functional)

\section{References}

1. Gold MC, Lewinsohn DM. Mucosal associated invariant T cells and the immune response to infection. Microbes Infect (2011) 13(8-9):742-8. doi:10.1016/j.micinf.2011.03.007

2. Gansert JL, Kiessler V, Engele M, Wittke F, Rollinghoff M, Krensky AM, et al. Human NKT cells express granulysin and exhibit antimycobacterial activity. J Immunol (2003) 170(6):3154-61. doi:10.4049/jimmunol.170.6.3154

3. Ferrick DA, Schrenzel MD, Mulvania T, Hsieh B, Ferlin WG, Lepper H. Differential production of interferon-gamma and interleukin-4 in response to Th1- and Th2-stimulating pathogens by gamma delta T cells in vivo. Nature (1995) 373(6511):255-7. doi:10.1038/373255a0 suggesting that DN or CD8 subsets are functionally distinct (12). However, to our knowledge, there are no other reports describing DN MAIT cell reactivity to pathogens. Here, we provide evidence that DN MAIT subsets are reactive to $H$. pylori and show that these responses are MR-1 restricted. In addition, our results demonstrate differences among the MAIT subsets in terms of their basal levels of activation and percentages, but not in the quality of responses, depending on whether they are in circulation or in the gastric mucosa.

In conclusion, we have demonstrated the presence of MAIT cells in the human stomach and its likely role in the host immune response to $H$. pylori infection as well as provided evidence for the role of $\mathrm{CD}^{+}$and DN MAIT cell subsets in infection.

\section{Author Contributions}

JB performed most of the experiments, contributed to study design, acquisition of data, analysis and drafting of the manuscript; RS-G contributed to study design, analysis, and drafting of the manuscript; TB prepared $H$. pylori antigens, performed bacteria entry assays, and reviewed the manuscript; LM prepared and quantified $H$. pylori cultures and reviewed the manuscript; HK, SP, and AS performed endoscopies, obtained gastric biopsies, and reviewed the manuscript; $B G$ performed endoscopies, obtained gastric biopsies and funding, and reviewed the manuscript; SC obtained funding and reviewed the manuscript; and MS designed the study, supervised the work, drafted the manuscript, and obtained funding.

\section{Acknowledgments}

We are indebted to the volunteers who allowed us to perform this study. We thank Onyinye Erondu, Robin Barnes, and the staff from the Recruiting Section of Center for Vaccine Development for their help in collecting gastric biopsies and blood specimens and Ms. Regina Harley and Catherine Storrer for excellent technical assistance. This work was funded by NIAID (NIH, DHHS) grant U19 AI082655 (Cooperative Center for Human Immunology; CCHI) to MS. LM was supported by Gastroenterology training grant NIH T32 DK767872.

\section{Supplementary Material}

The Supplementary Material for this article can be found online at http://journal.frontiersin.org/article/10.3389/fimmu.2015.00466

4. Le Bourhis L, Martin E, Peguillet I, Guihot A, Froux N, Core M, et al. Antimicrobial activity of mucosal-associated invariant T cells. Nat Immunol (2010) 11(8):701-8. doi:10.1038/ni.1890

5. Le Bourhis L, Guerri L, Dusseaux M, Martin E, Soudais C, Lantz O. Mucosalassociated invariant $\mathrm{T}$ cells: unconventional development and function. Trends Immunol (2011) 32(5):212-8. doi:10.1016/j.it.2011.02.005

6. Thomas SY, Hou R, Boyson JE, Means TK, Hess C, Olson DP, et al. CD1drestricted NKT cells express a chemokine receptor profile indicative of Th1-type inflammatory homing cells. J Immunol (2003) 171(5):2571-80. doi:10.4049/jimmunol.171.5.2571

7. O’Keeffe J, Doherty DG, Kenna T, Sheahan K, O’Donoghue DP, Hyland JM, et al. Diverse populations of $\mathrm{T}$ cells with NK cell receptors accumulate in 
the human intestine in health and in colorectal cancer. Eur J Immunol (2004) 34(8):2110-9. doi:10.1002/eji.200424958

8. O'Keeffe J, Gately CM, O'Donoghue Y, Zulquernain SA, Stevens FM, Moran AP. Natural killer cell receptor T-lymphocytes in normal and Helicobacter pylori-infected human gastric mucosa. Helicobacter (2008) 13(6):500-5. doi:10.1111/j.1523-5378.2008.00641.x

9. Hatz RA, Meimarakis G, Bayerdorffer E, Stolte M, Kirchner T, Enders G. Characterization of lymphocytic infiltrates in Helicobacter pylori-associated gastritis. Scand J Gastroenterol (1996) 31(3):222-8. doi:10.3109/ 00365529609004870

10. Booth JS, Toapanta FR, Salerno-Goncalves R, Patil S, Kader H, Safta A, et al. Characterization and functional properties of gastric tissue-resident memory T cells from children, adults and the elderly. Front Immunol (2014) 5:294. doi:10.3389/fimmu.2014.00294

11. Walker LJ, Kang YH, Smith MO, Tharmalingham H, Ramamurthy N, Fleming VM, et al. Human MAIT and CD8alphaalpha cells develop from a pool of type-17 precommitted CD8+ T cells. Blood (2012) 119(2):422-33. doi:10.1182/blood-2011-05-353789

12. Dusseaux M, Martin E, Serriari N, Peguillet I, Premel V, Louis D, et al. Human MAIT cells are xenobiotic-resistant, tissue-targeted, CD161hi IL-17secreting T cells. Blood (2011) 117(4):1250-9. doi:10.1182/blood-201008-303339

13. Gold MC, Cerri S, Smyk-Pearson S, Cansler ME, Vogt TM, Delepine J, et al. Human mucosal associated invariant $\mathrm{T}$ cells detect bacterially infected cells. PLoS Biol (2010) 8(6):e1000407. doi:10.1371/journal.pbio.1000407

14. Salerno-Goncalves R, Rezwan T, Sztein MB. B cells modulate mucosal associated invariant T cell immune responses. Front Immunol (2014) 4:511. doi:10.3389/fimmu.2013.00511

15. Wilson KT, Crabtree JE. Immunology of Helicobacter pylori: insights into the failure of the immune response and perspectives on vaccine studies. Gastroenterology (2007) 133(1):288-308. doi:10.1053/j.gastro.2007. 05.008

16. Windsor HM, Ho GY, Marshall BJ. Successful recovery of H. pylori from rapid urease tests (CLO tests). Am J Gastroenterol (1999) 94(11):3181-3. doi:10.1111/j.1572-0241.1999.01515.x

17. Sztein MB, Tanner MK, Polotsky Y, Orenstein JM, Levine MM. Cytotoxic T lymphocytes after oral immunization with attenuated vaccine strains of Salmonella typhi in humans. J Immunol (1995) 155(8):3987-93.

18. Rahn W, Redline RW, Blanchard TG. Molecular analysis of Helicobacter pylori-associated gastric inflammation in naive versus previously immunized mice. Vaccine (2004) 23(6):807-18. doi:10.1016/j.vaccine.2004.06.051

19. Zeaiter Z, Diaz H, Stein M, Huynh HQ. Helicobacter pylori induces expression and secretion of oncostatin M in macrophages in vitro. Dig Dis Sci (2011) 56(3):689-97. doi:10.1007/s10620-010-1341-z

20. Small PL, Isberg RR, Falkow S. Comparison of the ability of enteroinvasive Escherichia coli, Salmonella typhimurium, Yersinia pseudotuberculosis, and Yersinia enterocolitica. Infect Immun (1987) 55(7):1674-9.

21. Davies JQ, Gordon S. Isolation and culture of human macrophages. Methods Mol Biol (2005) 290:105-16. doi:10.1385/1-59259-838-2:105

22. Alter G, Malenfant JM, Altfeld M. CD107a as a functional marker for the identification of natural killer cell activity. J Immunol Methods (2004) 294(1-2):15-22. doi:10.1016/j.jim.2004.08.008

23. Le Bourhis L, Dusseaux M, Bohineust A, Bessoles S, Martin E, Premel V, et al. MAIT cells detect and efficiently lyse bacterially-infected epithelial cells. PLoS Pathog (2013) 9(10):e1003681. doi:10.1371/journal.ppat.1003681

24. Treiner E, Duban L, Bahram S, Radosavljevic M, Wanner V, Tilloy F, et al. Selection of evolutionarily conserved mucosal-associated invariant $\mathrm{T}$ cells by MR1. Nature (2003) 422(6928):164-9. doi:10.1038/nature01433
25. Leeansyah E, Loh L, Nixon DF, Sandberg JK. Acquisition of innate-like microbial reactivity in mucosal tissues during human fetal MAIT-cell development. Nat Commun (2014) 5:3143. doi:10.1038/ncomms4143

26. Tang XZ, Jo J, Tan AT, Sandalova E, Chia A, Tan KC, et al. IL-7 licenses activation of human liver intrasinusoidal mucosal-associated invariant $\mathrm{T}$ cells. J Immunol (2013) 190(7):3142-52. doi:10.4049/jimmunol.1203218

27. Lee OJ, Cho YN, Kee SJ, Kim MJ, Jin HM, Lee SJ, et al. Circulating mucosalassociated invariant $\mathrm{T}$ cell levels and their cytokine levels in healthy adults. Exp Gerontol (2014) 49:47-54. doi:10.1016/j.exger.2013.11.003

28. Novak J, Dobrovolny J, Novakova L, Kozak T. The decrease in number and change in phenotype of mucosal-associated invariant $\mathrm{T}$ cells in the elderly and differences in males and females of reproductive age. Scand J Immunol (2014) 80(4):271-5. doi:10.1111/sji.12193

29. Guarner J, Bartlett J, Whistler T, Pierce-Smith D, Owens M, Kreh R, et al. Can pre-neoplastic lesions be detected in gastric biopsies of children with Helicobacter pylori infection? J Pediatr Gastroenterol Nutr (2003) 37(3):309-14. doi:10.1097/00005176-200309000-00019

30. Queiroz DM, Rocha GA, Mendes EN, Carvalho AS, Barbosa AJ, Oliveira CA, et al. Differences in distribution and severity of Helicobacter pylori gastritis in children and adults with duodenal ulcer disease. J Pediatr Gastroenterol Nutr (1991) 12(2):178-81. doi:10.1097/00005176-199102000-00007

31. Bergman M, Del Prete G, van Kooyk Y, Appelmelk B. Helicobacter pylori phase variation, immune modulation and gastric autoimmunity. Nat Rev Microbiol (2006) 4(2):151-9. doi:10.1038/nrmicro1344

32. Bamford KB, Fan X, Crowe SE, Leary JF, Gourley WK, Luthra GK, et al. Lymphocytes in the human gastric mucosa during Helicobacter pylori have a T helper cell 1 phenotype. Gastroenterology (1998) 114(3):482-92. doi:10.1016/ S0016-5085(98)70531-1

33. O'Keeffe J, Moran AP. Conventional, regulatory, and unconventional T cells in the immunologic response to Helicobacter pylori. Helicobacter (2008) 13(1):1-19. doi:10.1111/j.1523-5378.2008.00559.x

34. Bhuiyan TR, Islam MM, Uddin T, Chowdhury MI, Janzon A, Adamsson J, et al. Th1 and Th17 responses to Helicobacter pylori in Bangladeshi infants, children and adults. PLoS One (2014) 9(4):e93943. doi:10.1371/journal.pone.0093943

35. Necchi V, Candusso ME, Tava F, Luinetti O, Ventura U, Fiocca R, et al. Intracellular, intercellular, and stromal invasion of gastric mucosa, preneoplastic lesions, and cancer by Helicobacter pylori. Gastroenterology (2007) 132(3):1009-23. doi:10.1053/j.gastro.2007.01.049

36. Corbett AJ, Eckle SB, Birkinshaw RW, Liu L, Patel O, Mahony J, et al. T-cell activation by transitory neo-antigens derived from distinct microbial pathways. Nature (2014) 509(7500):361-5. doi:10.1038/nature13160

37. Ussher JE, Klenerman P, Willberg CB. Mucosal-associated invariant T-cells: new players in anti-bacterial immunity. Front Immunol (2014) 5:450. doi:10.3389/fimmu.2014.00450

38. Cowley SC. MAIT cells and pathogen defense. Cell Mol Life Sci (2014) 71(24):4831-40. doi:10.1007/s00018-014-1708-y

Conflict of Interest Statement: The authors declare that the research was conducted in the absence of any commercial or financial relationships that could be construed as a potential conflict of interest.

Copyright (๑) 2015 Booth, Salerno-Goncalves, Blanchard, Patil, Kader, Safta, Morningstar, Czinn, Greenwald and Sztein. This is an open-access article distributed under the terms of the Creative Commons Attribution License (CC BY). The use, distribution or reproduction in other forums is permitted, provided the original author(s) or licensor are credited and that the original publication in this journal is cited, in accordance with accepted academic practice. No use, distribution or reproduction is permitted which does not comply with these terms. 